\title{
Artificial weathering of Spanish granites subjected to salt crystallization tests: Surface roughness quantification
}

\author{
P. López-Arce a,*, M.J. Varas-Muriel ${ }^{\text {a,c }}$, B. Fernández-Revuelta ${ }^{\text {b }}$, M. Álvarez de Buergo a ${ }^{\text {, }}$ \\ R. Fort ${ }^{\mathrm{a}}$, C. Pérez-Soba ${ }^{\mathrm{c}}$ \\ a Grupo de Petrología alicada a Conservación del Patrimonio, Instituto de Geologín Económic (CSIC-UCM), José Antonio Nováis 2, 28040, Madrid, Spain \\ b Laboratorio de Fiedra Natural, Instituto Geologico y Minero de España (IGME), Calera 1, 28760 Tres Cantos, Madrid, Spain

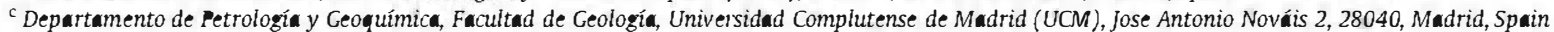

Keywords:

Granite

Salt crystallization tests

Weathering

Surface roughness indexes

Durability

Natural stone

\begin{abstract}
A B S T R A C T
For hundreds of years, two types of granite (Zarzalejo and Alpedrete) from the Madrid region, Spain, have been extensively used as building stones. Fresh specimens of both stone types have been sampled from their respective quarries and subjected to sodium sulphate salt crystallization test (SCT). The resulting physical and chemical weathering patterns have been characterized by polarized light optical and environmental scanning electron microscopy. Water absorption under vacuum conditions and mercury intrusion porosimetry techniques were used to determine the pre- and post-SCT porosity and pore size distribution. The following non-destructive techniques were performed to assess stone durability and decay: ultrasound velocity (US) and surface roughness determination (SR) of intra- and inter-granular quartz, feldspar and biotite minerals at the centre as well as at the corners and edges of specimen surfaces. Before the SCT, US values were lower and SR values higher in Zarzalejo (ZAR) than Alpedrete (ALP) granite. After SCT, the US values declined while SR rose in both types of granites, with greater average differences in ZAR than ALP for both parameters. Feldspar and biotite and their inter-granular contacts were found to be the weakest and therefore the most decay-prone areas of the stone.

The initial SR parameters were generally higher and rose more steeply after SCT at the corners and around the edges of the specimens.

While behaviour was found to be similar in the two types of granite, variations were greater in ZAR, the less durable and more decay-prone of the two. Surface roughness measurement of mineral grains in granite stones is a very useful, in situ, non-destructive technique for quantifying salt crystallization-mediated physical and chemical weathering. The resulting quantification of decay and of related durability provides insight into the future behaviour of this type of stone, commonly used in historic buildings.
\end{abstract}

\section{Introduction}

Granite is a stone traditionally used as a building material in central Spain, where it is known as Berroqueña stone, a name derived from the word "berrueco", a local term used to designate the spheroid granitic boulders generated by natural weathering (Røyne et al., 2008). The materials mostly used in traditional Madrilenian architecture are granite, limestone and brick. Granite has been and continues to be the rock most intensively quarried in the Spanish capital. Some of the region's granitoids, medium-grained and displaying frequently mafic micro-granular enclaves, would very likely never have been used as building materials if it was not for their local availability in quarries so close to the city of Madrid, a large and demanding consumer.

\footnotetext{
* Corresponding author.

E-mail address: plopezar@geo.ucm.es (P. López-Arce)
}

A number of studies have been published on granite weathering, and, more specifically, on the role that intra-granularmicrotexture and microstructure play in chemical and physical weathering processes and on the comparison between experimental and natural weathering in alkali feldspars (Lee and Parsons, 1995; Lee et al., 1998); the surface chemistry, etch pits and mineral-water reactions of minerals and the dissolution rate of quartz and (Lasaga and Blum, 1986; Blum et al., 1990), decay patterns in monumental granite (Matias and Alves, 2001); nature and decay effects of urban soiling on granitic building stones (Schiavon et al., 1995) or kaolinization processes on granitic building stone in urban environments (Schiavon, 2007). There are also works on biodeterioration of granite (Schiavon, 2002). Physical or mechanical weathering has also been explored in depth, with research focusing on areas such as: the role of microcracking in shear-fracture propagation (Moore and Lockner, 1995); the micro-effects of fire on granite, namely the generation of new and the growth of pre-existing fissures (Gómez-Heras et al., 2006); the influence of rift and bedding 
planes on the physical-mechanical properties of granitic rocks and the implications for granite monument decay (Rivas et al., 2000); microscopic observations and contact stress analyses of granite subjected to compression stress (Seo et al., 2002); the effect of foliation on the textural strength of granitic rocks (Akesson et al., 2003); the role of microfracture and porosity in the physicalmechanical properties and weathering of ornamental granite (Sousa et al., 2005); natural microcrack networks in granite affected by a fault zone (Onishi and Shimizu, 2005); and the use of fracture indexes to check the suitability of granite outcrops for quarrying (Sousa, 2007). Few studies have been conducted, however, on the evaluation of granite durability when used as a building stone and the selection of the most suitable parameters for this purpose. Haneef et al. (1993) conducted a laboratory simulation of degradation of granite by dry and wet deposition processes. A method for determining granite durability is artificial weathering via salt crystallization cycles (Rivas et al., 2008), but visual quantification of the weathering observed remains elusive.

The pressure generated by salt crystal growth in confined spaces in porous building materials such as stone, brick, and concrete is generally acknowledged to be a major cause of damage in both ancient monuments and modern buildings (Goudie and Viles, 1997; Doehne, 2002). Inasmuch as sodium sulphate is generally regarded to be particularly harmful, it is frequently used in accelerated weathering tests. Spanish and European standard UNE-EN 12370:1999 on natural stone test methods specifies that testing should be performed on materials with a porosity of over $5 \%$. Nonetheless, the method may also be useful in lower porosity stones such as granite, where salt may cause adverse effects due to the appearance of new or the widening of existing cracks (Alonso et al., 2008). A chemical replacement mechanism of granite minerals by gypsum has been claimed by Schiavon et ał (1995).

Weathering or durability is difficult to quantify in granite, however, since both are usually based on visual aspects or weight loss, which are particularly difficult to measure because the low open porosity of this stone determines a low salt solution uptake and penetration and therefore scant visual decay. Besides weight loss, other physical properties such as wave propagation, colour and surface roughness have been used to quantify the durability of ornamental granites affected by salt crystallization (Alonso et al., 2008). Hodson et al. (1997) determined surface roughness in unweathered alkali feldspar grains expressed as the ratio of specific surface (found by applying the BET isotherm to gas adsorption data) to the geometric area of mineral grains in a given size fraction. Gómez-Heras et al. (2006) used image processing to find the roughness index (RI(fs)) of burnt and unbumt granites based on parameters determined from segmented binary images. This RI(fs), which is defined as the ratio between fissure length and area, is useful to distinguish between open $(R I<1)$ and closed $(R I=1)$ fracture system pattems.

Nonetheless, very few natural stone studies based on surface roughness measurements have been conducted, and even fewer have addressed the use of such measurements to quantify durability. Furthermore, as information on the standard tests used to measure surface roughness, as well as on measuring conditions (such as the choice of the filters) and calculations, is missing in many papers, comparison of the results to the present findings is difficult.

Since the 1930s, when the first roughness metres appeared, surface texture measurement has been based on two-dimensional profilometry and contact gauges. The standardization and formalization of 3D texture analyses is presently underway (Blateyron, 2000). The stylus for 2D profilometry with a contact gauge is still in use today, and while it delivers lower precision and is more time-consuming, it is also more affordable. Further to the DIN EN ISO 3274:1996 standard test, in twodimensional surface tracing the stylus is dragged at a constant speed across the surface to be measured in a position normal to it. Furthermore, physical properties such as surface roughness can be used to quantify the physical-chemical weathering patterns that may or may not be observable under polarized optical or scanning electron microscopy.
The main aim of the present study was to assess decay patterns occurring after artificial weathering induced by $\mathrm{Na}_{2} \mathrm{SO}_{4}$ crystallization cycles in the two types of granite most commonly used for building construction in the city of Madrid, Spain: the Zarzalejo and Alpedrete granites. Decay assessment focused on the relationship between physical-chemical weathering features characterized under polarized light optical microscopy, environmental scanning electron microscopy, mercury intrusion porosimetry, water absorption and ultrasound propagation on the one hand, and the variation in surface roughness in mineral grains located on the surface edges, corners and centres of granite specimens on the other, as a method for quantifying decay and consequently durability of the two varieties of granite.

\section{Materials and methods}

\subsection{Granites}

\subsubsection{Geology}

The two types of granite used are quarried primarily in the southwestern region of the Guadarrama Mountains, a range in the eastern part of the Spanish Central System (SCS) shown in Fig. 1. The SCS is a Hercynian orogenic belt located in central Spain, bounded on the north and south by two Tertiary river basins, the Duero and the Tagus (Tajo), respectively. The SCS batholith comprises large volumes of peraluminous granites, which were emplaced onto high- to medium-grade metamorphic rocks during the late Hercynian orogeny (325 to $285 \mathrm{Ma}$; Villaseca et al., 1998; Villaseca and Herreros, 2000; Bea et al., 2004; Villaseca, 2003). The composition of these plutonic rocks is predominantly monzogranitic to leucogranitic, with minor basic to intermediate rocks (Gonzalez-Casado et al., 1996; Villaseca et al, 1998).

Although both are compositionally classified as monzogranites, the Alpedrete and Zarzalejo varieties are texturally and mineralogically different. The Zarzalejo granite pluton is located about $60 \mathrm{~km}$ northwest of the city of Madrid, at $1104 \mathrm{~m}$ above sea level. Two texturally different units can be distinguished: a relatively equigranular, medium- to coarse-grained, grey unit, and a porphyritic unit characterized by the presence of $\mathrm{K}$-feldspar megacrysts in a mediumgrained matrix. Microgranular mafic enclaves and xenoliths are occasionally found: They are usually sub-rounded or ellipsoidal and display a tonalitic composition. The major components are quartz, plagioclase, K-feldspar, and biotite (Fig. 2a); muscovite may occur as a secondary accessory mineral, along with a number of micaceous microcrystalline aggregates indicative of the transformation of cordierite.

The $350-\mathrm{km}^{2}$, irregular Alpedrete monzogranite pluton is located $45 \mathrm{~km}$ north of the city of Madrid, at $919 \mathrm{~m}$ above sea level. Petrographically, it is an equigranular, fine- to medium-grained, dark grey monzogranite to granodiorite pluton, although porphyritic varieties may also occur locally. The main petrographic characteristic of this variety is the abundance of microgranular mafic enclaves present in all the outcrops: their mineralogy consists chiefly of quartz, plagioclase, $\mathrm{K}$-feldspar and biotite, with variable amounts of accessory cordierite (Fig. 2b). Other accessory minerals commonly found include ilmenite, apatite, zircon and monacite (ITGE, 1990).

\subsubsection{Architectural use}

The granites used for testing were selected for their role in traditional construction in the region of Madrid, Spain. This study focused on two varieties of granites from abandoned quarries at Zaizalejo and Alpedrete, both located in the province of Madrid. These two materials are generally found in good state of conservation on many monuments and historical buildings in the city of Madrid and its surrounding region. Due to the wide temperature fluctuations between winter and summer typical of continental climates, flaking and granular disintegration are, though, sometimes visible in the granite on ground-level parts of the buildings (Menduiña et al., 2005). 

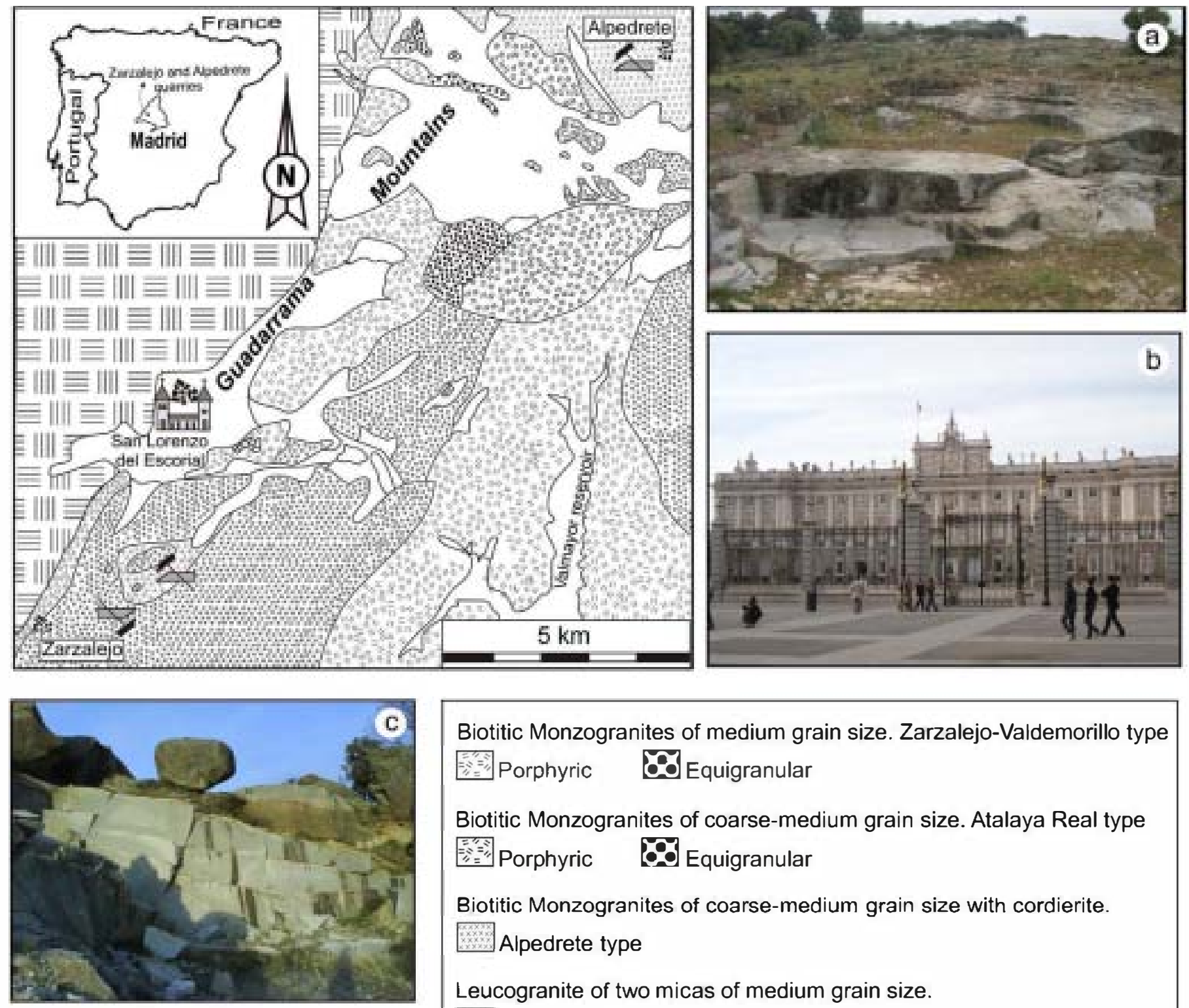

Biotitic Monzogranites of medium grain size. Zarzalejo-Valdemorillo type Eorphyric Equigranular

Biotitic Monzogranites of coarse-medium grain size. Atalaya Real type E": Equigranular

Biotitic Monzogranites of coarse-medium grain size with cordierite.

Alpedrete type

Leucogranite of two micas of medium grain size.

W. Machotas type

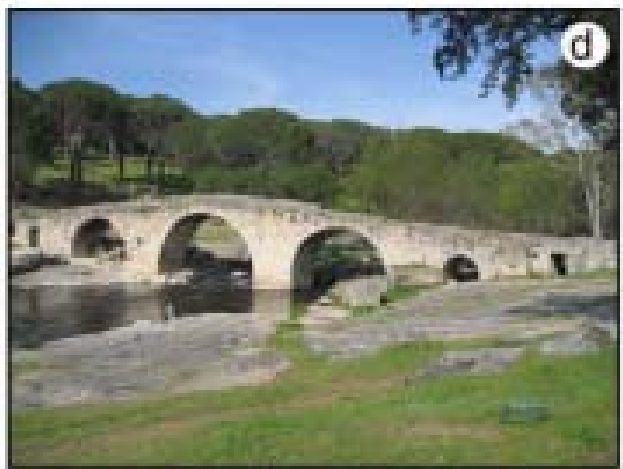

Leucogneis and glandular Ortogneis

$\overline{1 \omega}$

Sands, clays, granite and gneis boulder and pebbles

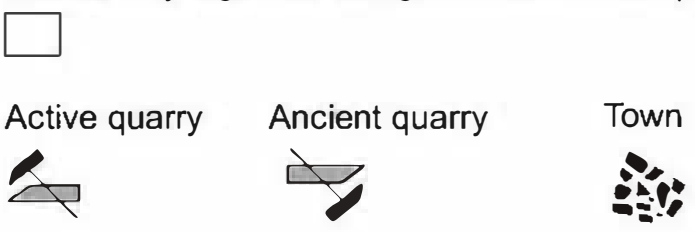

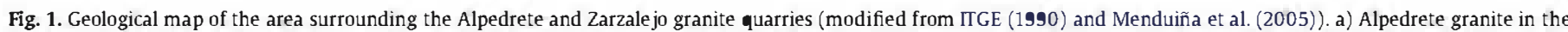
quarry and b) used as a building stone for Madrid Royal Palace. c) Zarzale jo granite in the quarry and d) used as building material for the Roman Valdemaqueda bridge.

Today what was known in the past as Zarzalejo granite is quarried and marketed under the rade names Blanco Rafaela (Rafaela White) or Gris Escorial (Escorial Grey) (Menduiña et al., 2005; Garcia del Cura et al., 2008). This granite was used to build many monuments of the region of Madrid from the 15th to the 17th centuries (Pérez-Monserrat and Fort, 2004). Stone on heritage monuments has likewise been replaced with Zarzalejo granite in recent years (Fort et al., 1996). Fig. 1a shows the Alpedrete quarry; Fig. 1b shows a monument built with this type of 

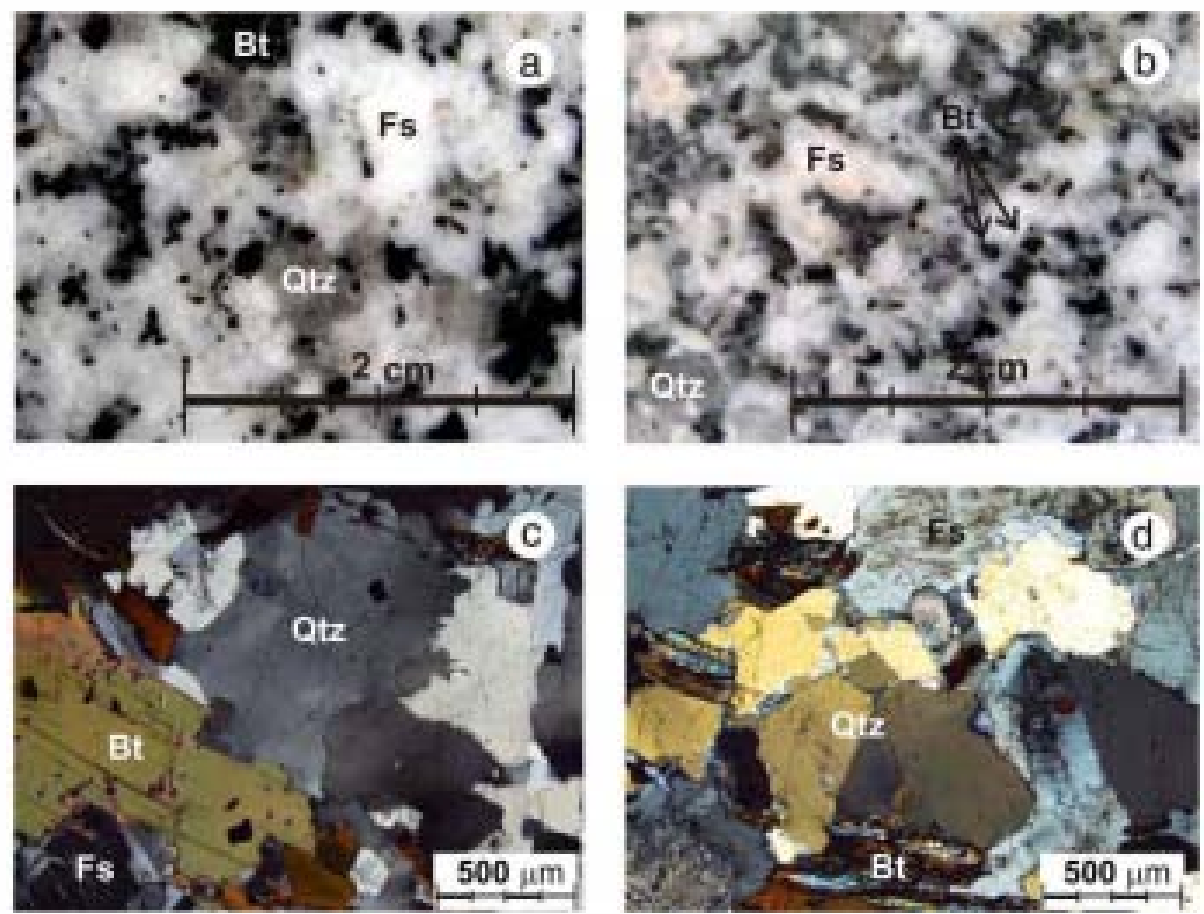

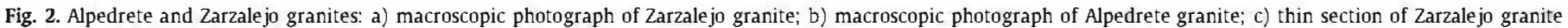
under PLOM; d) thin section of Alpedrete granite under PLOM. Bt: biotite; Qtz: quartz; Fs: feldspar.

granite (Royal Palace atMadrid); Fig. 1c shows the Zarzalejo quarry and Fig. 1d shows a Roman monument built with this granite (Valdemaqueda bridge).

\subsubsection{Granite samples}

Fifty five cubic ( $50 \pm 5-\mathrm{mm}$ ) specimens (rather than the $40 \pm 1$ $\mathrm{mm}$ cubes prescribed in the RIIEM recommendations on dimensions for durability standard test) were obtained for each type of stone. The specimens were cut with a Diamant Boart, Scut Mixed Granite diamond blade saw, fitted with a $350-\mathrm{mm}$ diameter disc having $40 \mathrm{~mm}$ wide, $3 \mathrm{~mm}$ thick and $10 \mathrm{~mm}$ high segments with micronscale diamonds.

The cubic specimens were used for both the salt crystallization ageing test and to determine the petrophysical properties of the stone, before and after $\mathrm{Na}_{2} \mathrm{SO}_{4}$ exposure.

\subsection{Salt crystallization test (SCT)}

The selection of samples was based on anisotropy indexes following the criteria set out in Fort et al. (2008) for the salt crystallization-induced accelerated ageing test and according to Spanish and European standard UNE-EN 12370:1999. In this test, specimens were immersed in a sodium sulphate solution (14\% decahydrate, density $=1.055 \mathrm{~g} / \mathrm{cm}^{3}$ ) for $2 \mathrm{~h}$ at $20.0 \pm 0.5^{\circ} \mathrm{C}$ and oven-dried for at least $16 \mathrm{~h}$ at $105 \pm 5^{\circ} \mathrm{C}$. They were then allowed to cool to room temperature for $2 \mathrm{~h}$ before starting the next cycle. Pursuant to standard test requirements, the specimens were initially subjected to 15 such salt crystallization cycles. Due to the low open porosity of granite and the scant weight loss and decay recorded in this first series, however, the specimens were subjected to a second round of 15 cycles. Consequently, the test specimens were subjected to a total of 30 salt crystallization cycles prior to their characterization. The samples were rinsed daily after the cycles to eliminate all salt, as defined by conductivity values declining below the $20 \mu \mathrm{S} / \mathrm{m}$ mark.

\subsection{Characterization analyses}

\subsubsection{Polarized light optical microscopy (PLOM)}

The surface of the specimens was studied before and after SCI under polarized light optical microscopy (PLOM) to characterize mineralogy and physical-chemical weathering patterns. Grain sizes and percentage volumes were roughly estimated. Thin sections of stone were studied with an Olympus BX51 polarized light microscope fitted with an Olympus DP $12(6 \mathrm{~V} / 2.5 \AA)$ digital camera.

\subsubsection{Environmental scanning electron microscopy (ESEM)}

Eight-millimetre cubes were cut from the corners of the specimens to study granite fractures and fissures in a near-natural state with an Inspect FEI environmental scanning electron microscope (ESEM) with an Oxford Instrument Analytical 7509 energy dispersive X-ray spectroscope. Environmental microscopy is used to analyze roughness non-destructively, for it eliminates the need for more destructive rock polishing. The physical-chemical weathering patterns were observed before and after the SCT cycles.

\subsubsection{Surface roughness testing (SR)}

Surface roughness (SR) was measured with a stylus instrument, 2D profilometry with contact gauge Mitutoyo Surftest SJ-201P tester fitted with a $2-\mu \mathrm{m}$ diamond tip stylus, at an applied load of $0.75 \mathrm{mN}$ and a measuring speed of $0.5 \mathrm{~mm} / \mathrm{s}$. The maximum measuring range along the $\mathrm{Z}$ axis was $350 \mu \mathrm{m}$ and along the $\mathrm{X}$ axis, $12.5 \mathrm{~mm}$. A total of 1152 roughness profiles were obtained from four fresh and four salt-weathered specimens of each type of granite. Seventy-two profiles were obtained for each specimen on any of their surfaces. Thirty-six profiles were based on intra-granular and the other thirtysix on inter-granular measurements (Fig. 3).

Each primary (or P-) profile was filtered to obtain the mean line with which to find the surface roughness parameters. The filtered profile (roughness or R-profile), whose total length is called the evaluation length, was divided into a number of sampling lengths, depending on the length of another profile filter. This latter filter, 

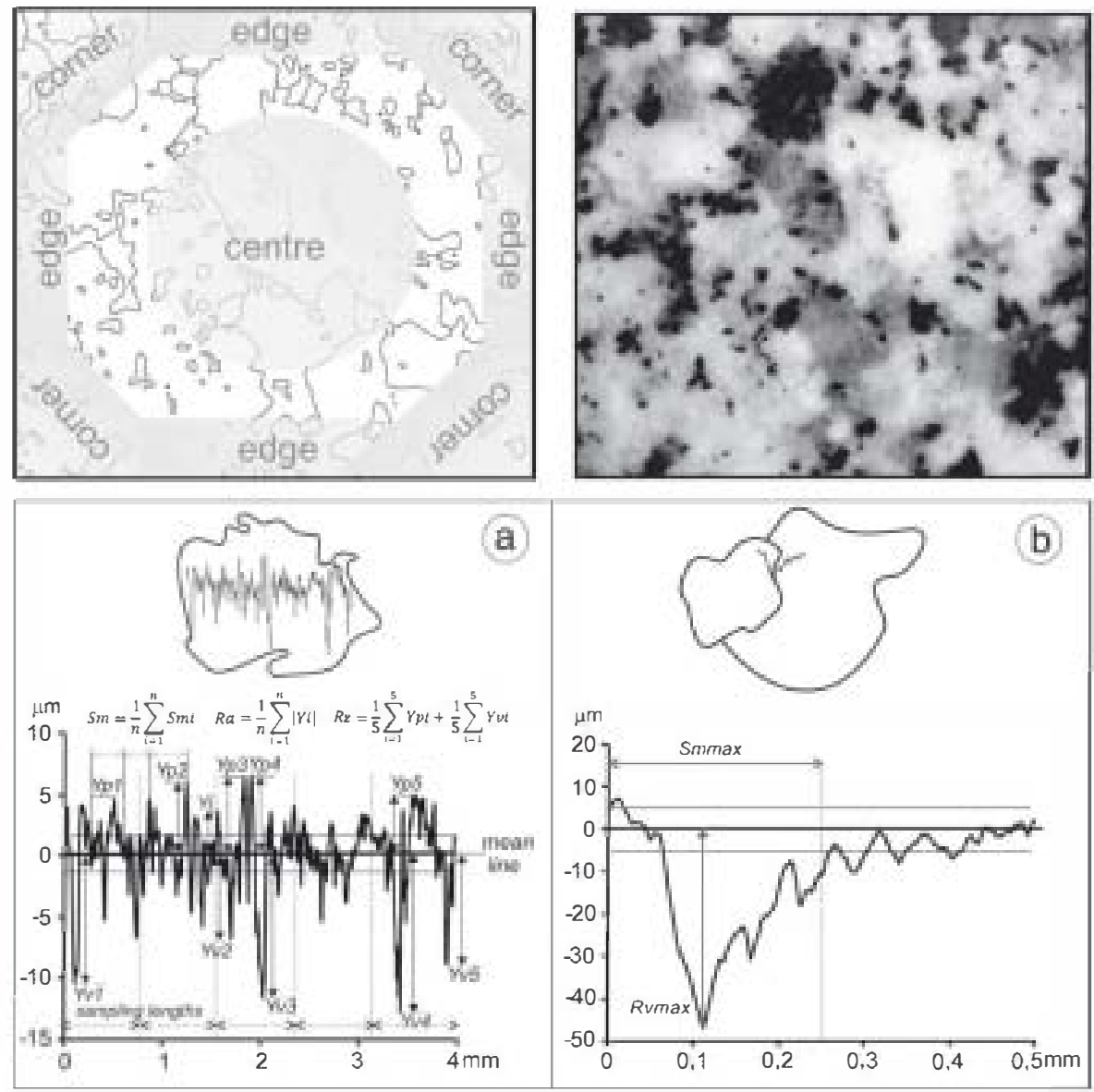

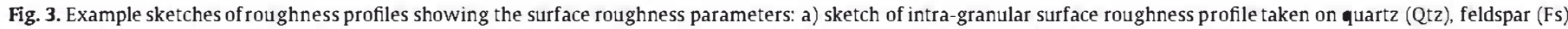

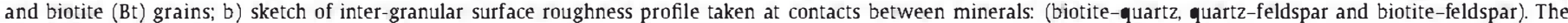
measurements were taken at the centre, corners and edges of the surface of granite specimens (top left image).

known as the cut-off, was applied to delimit wavelengths denoting roughness and those denoting waviness.

Thirty-six 4-mm profiles (with a standard 0.8-mm cut-off) were obtained from the intra-granular measurements relative to the following three main mineral grains: quartz, feldspar and biotite. Some of the biotite profiles (particularly in Alpedrete granite, which has smaller grain sizes) were $2.4 \mathrm{~mm}$ long with a standard 0.8 -mm cut-off. The other thirtysix profiles, $0.5 \mathrm{~mm}$ long (with a standard $0.25-\mathrm{mm}$ cut-off), were obtained from the measurements taken at the inter-granular contacts between minerals: biote-quartz (Bt-Qtz), quartz-feldspar (Qtz-Fs) and biotite-feldspar (Bt-Fs). In each case, four surface measurements were taken at the corners, four on the edges and four in the centre of the faces of the granite specimen. The roughness parameters analyzed in the intragranular study (Fig. 3a) were calculated and defined as stipulated in standard ISO 4287:1984. (i) $R a$ is the arithmetic mean of the absolute values of profile deviations from the mean. (ii) $R z$ is the sum of the vertical distances between the five highest peaks and the five deepest valleys within the sampling length (although in some profiles with few peaks, $R z$ was calculated with less than five peaks). (iii) $\mathrm{Sm}$ is the mean spacing between profile irregularities. The roughness parameters analyzed in the inter-granular study (Fig. 3b), in turn, were: Rvmax, the absolute value of the minimum value of the profile deviation from the mean line, i.e., the deepest point on the roughness profile (R-profile); and Smmax, the absolute value of the maximum spacing between profile irregularities.

\subsubsection{Ultrasonic velocity (US)}

Ultrasonic velocity ( $\mathrm{Vp}$ or P-wave velocity) was measured to evaluate decay non-destructively before and after SCT. P-wave propagation time was measured to a precision of $0.1 \mu$ s with a PUNDIT CNS Electronics US instrument. Standard recommendations were followed, except for: (i) specimen shape and size (cubic, with $50 \pm 5$-mm sides instead of the prismatic specimens prescribed in Spanish and European standard UNE-EN 14579: 2005 on sound speed propagation); and (ii), the frequency of the transducers used, which was $1 \mathrm{MHz}$. The diameter of the flat contact area on these transducers was $11.82 \mathrm{~mm}$. The bond between the transducers and the surface of the specimens was secured with a water and carboxymethylcellulose paste (Sichozell Kleister, Henkel). Measurements were taken in direct transmission/reception mode, across opposite parallel sides of the cubic specimens in all three spatial directions.

\subsubsection{Water absorption under vacuum}

In addition to the variation in sample weight, water absorption, pre- and post-SCT open porosity and bulk density were found for the 5-cm cubic specimens, as described in Spanish and European standard UNE-EN 1936: 1999 on natural stone test methods, determination of real density and apparent density and total and open porosity. Although this standard has now been replaced by UNE-EN 1936: 2007, the 1999 edition was in effect when the trials were begun and therefore was the one used throughout the experiment.

\subsubsection{Mercury intrusion porosimetry (MIP)}

Mercury intrusion porosimetry (MIP) was applied to surface sections before and after SCT to assess sample pore structure, i.e., total porosity ( $\mathrm{P}$ ) and pore size distribution (PSD). Readings were taken in pore diameters of 0.005 to $400 \mu \mathrm{m}$ under measuring conditions 
ranging from atmospheric pressure to 60,000 psia (228 MPa). Sample cores $10 \mathrm{~mm}$ in diameter and at least $30 \mathrm{~mm}$ high were cut and analyzed with a Micromeritics Autopore IV 9500 MIP.

\section{Results}

\subsection{Mineralogy and physical-chemical weathering under PLOM and ESEM}

Both natural (pre-SCГ) and salt crystallization-induced (post-SCГ) physical-chemical weathering of the two granite samples were examined on thin sections under polarized light optical microscopy (PLOM) and environmental scanning electron microscopy (ESEM). The pre-SC $\Gamma$ thin sections showed that Zaizalejo monzogranite had a coarse- to mediumgrained inequigranular texture (Fig. 2a and c), with sporadic K-feldspar phenocrysts $(1-3 \mathrm{~cm})$. The components of this grey rock are plagioclase (35 vol.\%), quartz (2-5 mm and 30 vol.\%), K-feldspar (2-8 $\mathrm{mm}$ and 20 vol.\%), and biotite (2-4 nm and 15 vol.\%). The main accessory minerals are apatite, ilmenite and zircon.

The natural chemical weathering of Zarzalejo monzogranite showed some transformation of biotite into chlorite, and extensive plagioclase and minor K-feldspar crystal seritization. Brittle deformation, mainly in quartz crystals which displayed considerable undulatory extinction, sutured intra-granular edges and frequent recrystallization into polycrystalline aggregates, the presence of $V$-shaped polysynthetic twins in many plagioclase crystals and local kink-bands and exfoliation dislocations in biotite are signs of natural physical weathering. Numerous intra-granular and inter-granular microfractures were present in feldspars and quartz.

Alpedrete monzogranite proved to be a medium- to fine-grained, equigranular, dark grey rock (Fig. $2 \mathrm{~b}$ and d) consisting of interlocking plagioclase aggregates (30 vol.\%), quartz (2-5 $\mathrm{mm}$ and $25 \mathrm{vol} . \%), \mathrm{K}-$ feldspar ( $1-4 \mathrm{~cm}$ and $35 \mathrm{vol} . \%$ ) and biotite ( $2 \mathrm{~mm}$ and $10 \mathrm{vol} . \%)$. Other accessory minerals include ilmenite, apatite and zircon. Evidence for natural physical weathering was found primarily in quartz crystals, which exhibited undulatory extinction and sutured intra-granular edges, $\mathbf{V}$-shaped twins in many plagioclase crystals and occasional kink-bands in biotite crystals. An abundance of microfractures was observed in quartz and feldspar crystals.

No significant mineralogical changes were found in both Alpedrete and Zarzalejo monzogranite samples after the salt crystallization test. However, the natural physical weathering is increased after the salt crystallization test due to the increase of intra-granular and intergranular microfractures, especially in feldspar crystals and the opening of cleavage planes in biotite crystals (Fig. $4 \mathrm{a}$ and e). In light of the risk of microfractures and microfissures production during thin section preparation, in the present study environmental scanning electron microscopy (ESEM) was used only to acquire visual information on these features in weathered granite samples, while decay quantification was performed on the basis of surface roughness trials. ESEM studies were, then, conducted on sample comers (8-nm cubes), as the most visibly weathered part of the 5-cm cubic specimens. Fresh samples of both ZAR and AIP were barely weathered, with only a few intra- or inter-granular fissures due to natural weathering. After the SCГ, the number of intra- and trans-granular fissures increased, particularly in the case of ZAR samples: fissures were mainly generated at and developed along the basal cleavage planes of biotite, to subsequently expand by circling quartz and cutting across feldspar grains (Fig. 4a and b). Radial fissures were also observed in the potassium feldspars surrounding biotite grains (Fig. 4b). This suggests that the opening of biotite planes during the salt crystallization test could generate stress forces within the crystal structure, resulting in the development of cutting across fissures. Physical weathering patterns induced by sodium sulphate crystallization between mineral grains are shown in Fig. $4 \mathrm{c}$ and d. Mineral fragments $(10-12 \mu \mathrm{m})$ were observed at the ZAR intergranular contacts. Fracturing would seem to have been induced by the salt crystallization process, for the fragments were detected in the postSCT samples but not in fresh ZAR samples; none of the foregoing was observed in the ALP sample before or after the SCT. The EDS analyses of these micro-fragments revealed the presence of $\mathrm{Si}, \mathrm{Al}, \mathrm{K}, \mathrm{Ca}$ and $\mathrm{Na}$, consistent with potassium feldspars and plagioclase composition. Pits and other signs of corrosion (Fig. $4 \mathrm{c}$ and $\mathrm{f}$ ) attributable to natural weathering were also observed in plagioclase, but these developments may well have been intensified as a result of sodium sulphate crystallization.

\subsection{Intra- and inter-granular surface roughness}

\subsubsection{Intra-granular surface roughness}

3.2.1.1. ZAR granite. The variation in the roughness parameters $(R a, R z$ and $S m$ ) relating to the three selected mineral grains (quartz, feldspar and biotite) and measured respectively at the centre, corners and edges of the surface of the four ZAR specimens before and after SCT is given in Table 1. In the mineral grains located at the centre of the fresh specimen (pre-SCI) surface, the lowest values of $R a$, or the arithmetic mean of the profile deviation from the mean, were found for biotite $(3.73 \pm 1.22 \mu \mathrm{m})$, followed very closely by feldspar $(3.94 \pm 0.35 \mu \mathrm{m})$; quartz values $(5.99 \pm 1.41 \mu \mathrm{m})$ were somewhat distant. In fresh samples, the mean deviation was slightly higher for the corner and edge locations as compared with the centre ones. Considerable differences were found between the pre- and post-SCГ (weathered sample) values: the lowest $R a$ values in the centre of the samples were recorded for feldspar $(6.33 \pm 0.22 \mu \mathrm{m}$, up by $61 \%)$, followed by biotite $(8.06 \pm 2.16 \mu \mathrm{m}, 116 \%$ higher $)$ and quartz $(9.46 \pm 2.14 \mu \mathrm{m}, 58 \%$ over the fresh sample values). The difference between the values for the corners and edges of fresh and weathered samples was even greater ( $138 \%$ increase in biotite, $124 \%$ in feldspars and $47 \%$ in quartz). No distinction could be drawn between results for corners and edges: in some cases, the differences between fresh and weathered samples were larger in the former while in others the inverse relationship applied. Some examples of pre- and post-SCT intra-granular roughness profiles for the three types of mineral grains at the corners and edges of ZAR specimens are shown in Fig. 5.

The results for parameter $R z$ are given in Table 1, which show that the lowest pre-SC $\Gamma$ values in the ZAR specimen were recorded for feldspar grains (average of $15.1 \pm 1.66 \mu \mathrm{m})$, followed by biotite $(17.18 \pm$ $3.97 \mu \mathrm{m})$ and quartz $(23.46 \pm 4.14 \mu \mathrm{m})$. The $R z$ values were very similar in the centre and on the edges for all the minerals and at the corners for feldspar, whereas the corner biotite and quartz grains exhibited higher values. After the SCT, the biotite and quartz values were very similar in all three locations (average of $34.67 \pm 6.46 \mu \mathrm{m}$ for biotite and $34.87 \pm 8.01 \mu \mathrm{m}$ for quartz), although the average increase in $R z$ was smaller for quartz (around $49 \%$ compared to $102 \%$ for biotite). The $R z$ values for feldspar rose from $15.38 \pm 1.59 \mu m$ to $22.76 \pm 0.89 \mu \mathrm{m}$ (up $48 \%$ ) in central grains, from $15.78 \pm 2.18 \mu \mathrm{m}$ to $29.42 \pm 3.67 \mu \mathrm{m}$ (up 86\%) at the corners, and from $14.14 \pm 1.2 \mu \mathrm{m}$ to $33.66 \pm 7.84 \mu \mathrm{m}$ (a 138\% rise) along the edges of the specimens. Table 1 shows the $S m$ values i.e., the mean spacing between profile irregularities obtained in ZAR sample. The highest $S m$ values before and after SCT were recorded for biotite, which exhibited similar values in the centre and on the corners and edges of samples, although the values were somewhat higher in the latter location. The mean pre-SCГ Sm value for biotite was $0.23 \pm 0.02 \mathrm{~mm}$. After the SCT, this value rose by around 36\%. The average pre-SC S Sm for quartz grains was $0.21 \pm 0.02 \mathrm{~mm}$. After the test, this value rose (19\%) up to $0.24 \pm 0.04 \mathrm{~mm}$. While the lowest $S m$ values before and after the SCI were found for feldspar grains, they were very similar to findings for the quartz grains. The mean $S m$ value for feldspar prior to the SCTwas $0.18 \pm 0.02 \mathrm{~mm}$. After the SC $\Gamma$ this value rose to $0.24 \pm 0.02 \mathrm{~mm}$.

3.2.1.2. ALP granite. The variation in roughness parameter $R a$ for the three selected mineral grains measured at the centre, corners and 

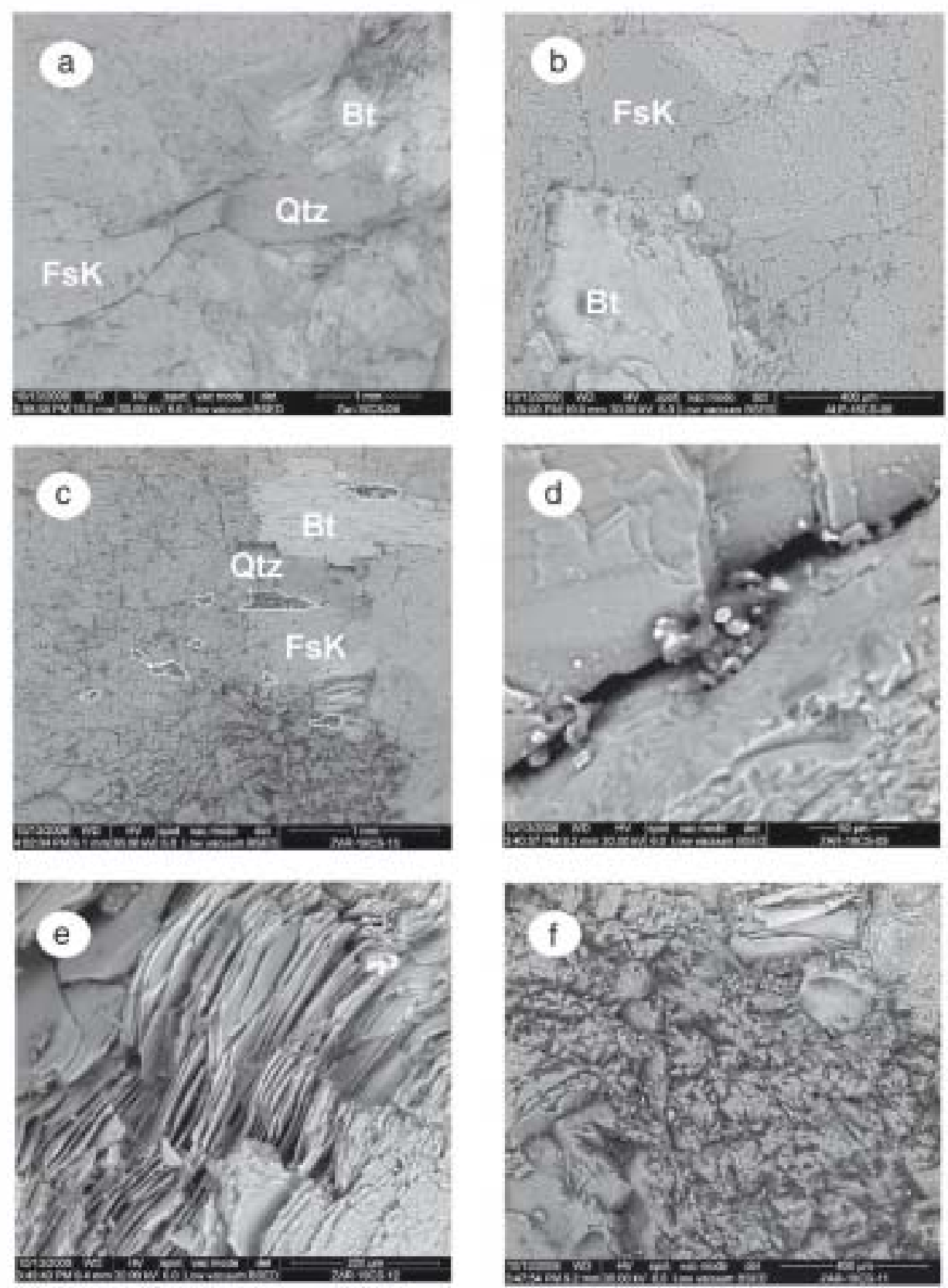

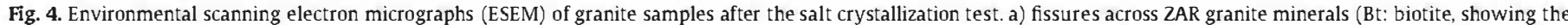

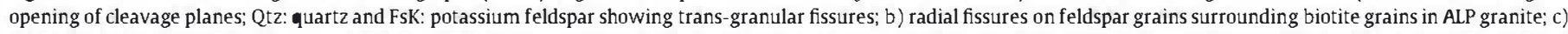

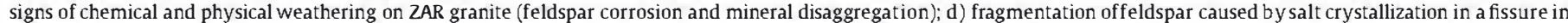
ZAR granite; e) detail of biotite showing the opening of cleavage planes; f) corrosion pits in feldspar grain.

edges of the surface of ALP granite before and after SCT is given in Table 2. The lowest $R a$ (profile deviation from the mean) values for the mineral grains located at the centre of the fresh specimen (pre-SC $\Gamma$ ) surface were found for feldspar $(2.90 \pm 0.56 \mu \mathrm{m})$, followed by biotite $(3.31 \pm 1.34 \mu \mathrm{m})$ and quartz $(3.66 \pm 0.55 \mu \mathrm{m})$. The values measured on the corners and edges were very similar. The most significant difference in $R a$ values taken at the centre of the ALP sample before and after the ageing test was recorded for feldspar (with a post-test value of $5.89 \pm 2.32 \mu \mathrm{m}$, up by approximately $103 \%$ with respect to the fresh sample). The post-SCI Ra value for biotite in the centre of the specimen was $5.46 \pm 0.54 \mu \mathrm{m}$, up to approximately $65 \%$ over the fresh specimen. The greatest increase for the corner and edge grains was found for biotite (with pre-SCГ values of $3.14 \pm 0.39 \mu \mathrm{m}$ at the corners and $3.25 \pm 0.47 \mu \mathrm{m}$ on the edges, and post-SC $\Gamma$ means of $6.83 \pm 1.74 \mu \mathrm{m}$ at the corners and $7.57 \pm 1.67 \mu \mathrm{m}$ on the edges, corresponding to an increase of approximately $117 \%$ and $133 \%$, respectively). The increase in the $R a$ value for feldspar located on specimen corners and edges was only slightly lower than that for biotite (with before SC $\Gamma$ values of $2.74 \pm 0.61 \mu \mathrm{m}$ at the corners and $2.98 \pm 0.48 \mu \mathrm{m}$ on the edges, and after SC $\Gamma$ means of $5.97 \pm 1.10 \mu \mathrm{m}$ at the corners and $5.45 \pm 0.54 \mu \mathrm{m}$ on the edges, corresponding to an increase of approximately $118 \%$ and $83 \%$, respectively). For quartz grains in turn, the rise in $R a$ values after the SC $\Gamma$ was very similar for all three locations (with an average value of $5.75 \pm 1.18 \mu \mathrm{m}$ and an average increase of $52 \%$ ).

In ALP sample, the lowest pre-SC $R z$ values (Table 2) were also recorded for feldspar grains (average of $11.65 \pm 1.77 \mu \mathrm{m}$ ), followed by biotite (average of $14.01 \pm 3.2 \mu \mathrm{m}$ ) and quartz (average of $15.64 \pm 2.7 \mu \mathrm{m}$ ). The central, edge and corner values were very similar for all the mineral grains both before and after the salt crystallization 
Table 1

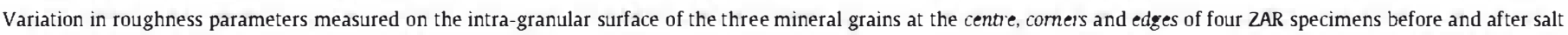

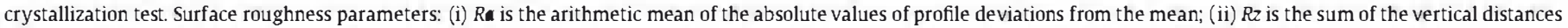
between the five highest peaks and the five deepest valleys within the sampling length; and (iii) $5 m$ is the mean spacing between profile irregularities.

\begin{tabular}{|c|c|c|c|c|c|c|}
\hline \multirow{2}{*}{$\frac{\mathrm{RP}}{\text { Mineral }}$} & \multicolumn{2}{|l|}{$R \boldsymbol{a}(\mu \mathrm{m})$} & \multicolumn{2}{|l|}{$R z(\mu \mathrm{m})$} & \multicolumn{2}{|c|}{$S m[10,000 \%](\mathrm{mm})$} \\
\hline & Before & After & Before & After & Before & After \\
\hline \multicolumn{7}{|l|}{ Biotite } \\
\hline Centre & $3.73 \pm 1.22$ & $8.06 \pm 2.16$ & $16.24 \pm 4.70$ & $31.02 \pm 7.80$ & $0.24 \pm 0.02$ & $0.26 \pm 0.05$ \\
\hline Corners & $4.39 \pm 1.80$ & $9.59 \pm 1.77$ & $20.46 \pm 4.8$ & $38.29 \pm 3.73$ & $0.22 \pm 0.02$ & $0.29 \pm 0.08$ \\
\hline Edges & $3.49 \pm 0.75$ & $9.18 \pm 2.39$ & $14.84 \pm 2.42$ & $34.71 \pm 7.86$ & $0.24 \pm 0.03$ & $0.35 \pm 0.07$ \\
\hline \multicolumn{7}{|l|}{ Quartz } \\
\hline Centre & $5.99 \pm 1.41$ & $9.46 \pm 2.14$ & $22.66 \pm 4.73$ & $34.73 \pm 6.25$ & $0.19 \pm 0.02$ & $0.25 \pm 0.04$ \\
\hline Corners & $7.49 \pm 0.91$ & $8.92 \pm 2.24$ & $27.55 \pm 3.49$ & $32.49 \pm 9.46$ & $0.25 \pm 0.04$ & $0.24 \pm 0.03$ \\
\hline Edges & $5.52 \pm 1.37$ & $10.23 \pm 2.72$ & $20.19 \pm 4.20$ & $37.38 \pm 8.33$ & $0.19 \pm 0.01$ & $0.24 \pm 0.04$ \\
\hline \multicolumn{7}{|l|}{ Feldspar } \\
\hline Centre & $3.94 \pm 0.35$ & $6.33 \pm 0.22$ & $15.38 \pm 1.59$ & $22.76 \pm 0.89$ & $0.18 \pm 0.02$ & $0.21 \pm 0.01$ \\
\hline Corners & $3.94 \pm 0.69$ & $7.98 \pm 1.07$ & $15.78 \pm 2.18$ & $29.42 \pm 3.67$ & $0.18 \pm 0.02$ & $0.25 \pm 0.02$ \\
\hline Edges & $3.71 \pm 0.28$ & $9.16 \pm 1.49$ & $14.14 \pm 1.20$ & $33.66 \pm 7.84$ & $0.18 \pm 0.02$ & $0.26 \pm 0.03$ \\
\hline
\end{tabular}

test, with the exception of the post-SCT corner and edge biotite, which showed a higher $R z$. Quartz and feldspar exhibited very similar post-SCT values (means of $21.38 \pm 4.03 \mu \mathrm{m}$ and $21.41 \pm 5.00 \mu \mathrm{m}$, respectively), but the average $R z$ increase was lower for quartz (about $37 \%$ and $84 \%$ for feldspar). The $R z$ values for biotite rose from $14.33 \pm 6.0 \mu \mathrm{m}$ to $24.71 \pm 3.8 \mu \mathrm{m}$ (up $72 \%$ ) in central grains, from $12.91 \pm 1.0 \mu \mathrm{m}$ to $28.41 \pm 6.3 \mu \mathrm{m}$ (up 120\%) at the corners, and from $13.89 \pm 2.17 \mu \mathrm{m}$ to $31.86 \pm 8.75 \mu \mathrm{m}$ (for a rise of $129 \%$ ) along the edges of the specimens.

Table 2 show the $S m$ values in ALP sample. The highest $S m$ values, before and after the SCT, were recorded for biotite, which exhibited similar values in the centre and on the corners and edges of samples, although the values were somewhat higher in the latter location. The mean pre-SCT Sm value for biotite was $0.21 \pm 0.04 \mathrm{~mm}$. After the SCT, these values rose by around 36\%. The average pre-SCT Sm for quartz grains was $0.18 \pm 0.03 \mathrm{~mm}$. After the test, this value rose $19 \%$ up to $0.21 \pm 0.02 \mathrm{~mm}$. While the lowest $S m$ values, before and after the SCT, were found for feldspar grains, they were very similar to findings for the quartz grains. The mean $S m$ value for feldspar was $0.17 \pm 0.02 \mathrm{~mm}$. After the SCT this value rose to $0.22 \pm 0.04 \mathrm{~mm}$, a $28 \%$ increase.

\subsubsection{Inter-granular surface roughness}

Examples of inter-granular roughness profiles for the three selected types of mineral grains at the corners and edges of ALP specimens before and after the SCT are shown in Fig. 6. The variation
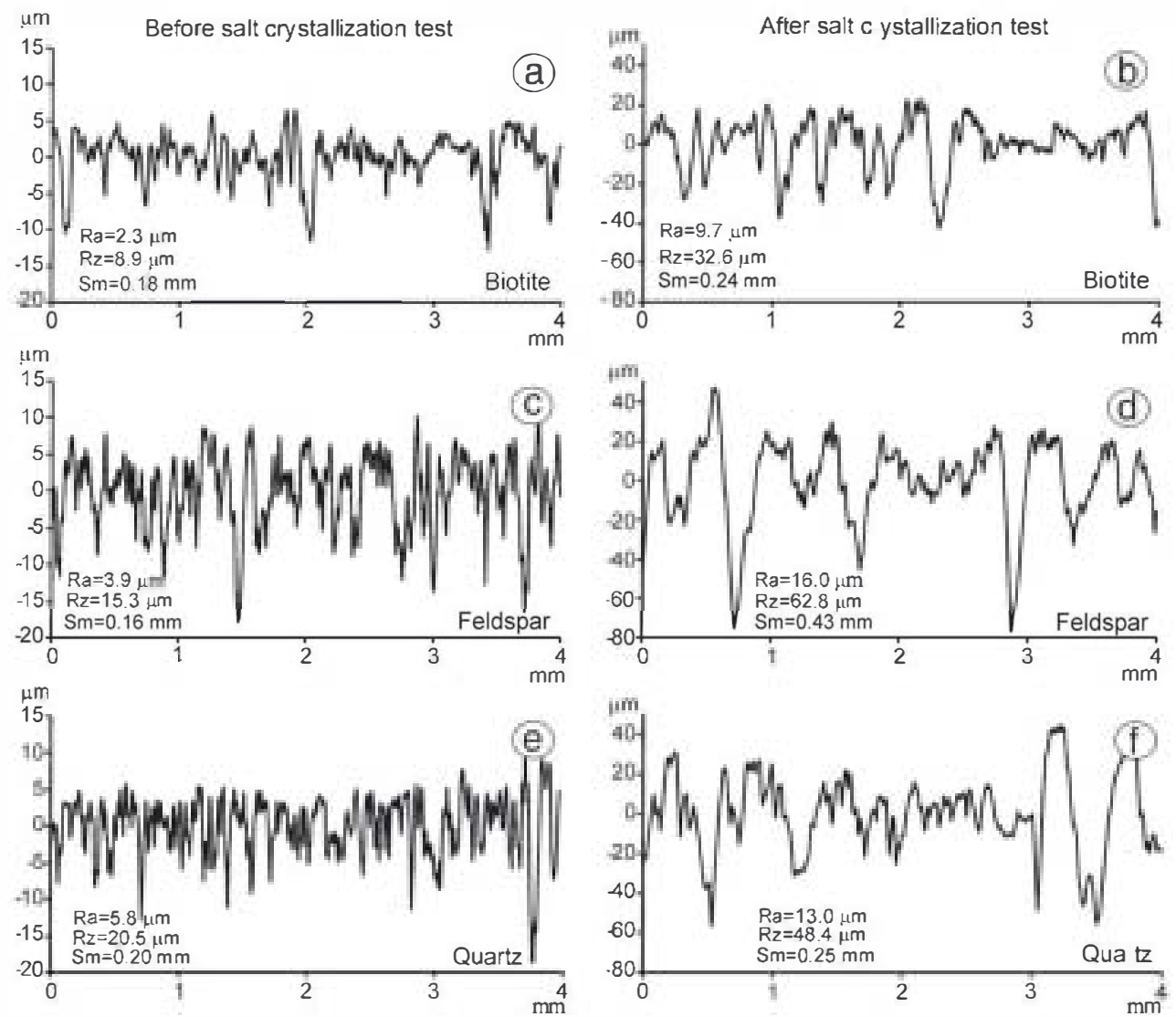

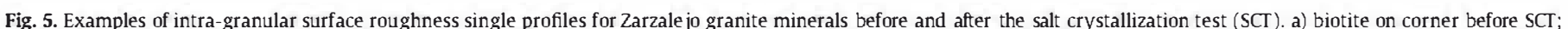

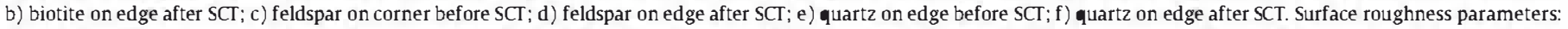

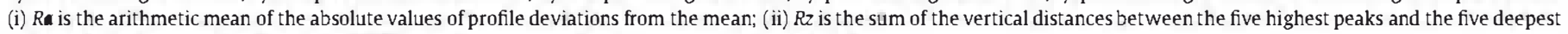
valleys within the sampling length; and (iii) $S m$ is the mean spacing between profile irregularities. 
Table 2

Variation in roughness parameters measured on the intra-granular surface of the three mineral grains at the centre, corners and edges of ALP specimens before and after salt crystallization test.

\begin{tabular}{|c|c|c|c|c|c|c|}
\hline \multirow{2}{*}{$\frac{\mathrm{RP}}{\text { Minerals }}$} & \multicolumn{2}{|l|}{$R(\mu \mathrm{m})$} & \multicolumn{2}{|l|}{$R z(\mu \mathrm{m})$} & \multicolumn{2}{|c|}{$\operatorname{Sm}[10,000 \%](\mathrm{mm})$} \\
\hline & Before & After & Before & After & Before & After \\
\hline \multicolumn{7}{|l|}{ Biotite } \\
\hline Centre & $3.31 \pm 1.34$ & $5.46 \pm 0.54$ & $14.33 \pm 5.98$ & $24.71 \pm 3.81$ & $0.22 \pm 0.07$ & $0.29 \pm 0.04$ \\
\hline Corners & $3.14 \pm 0.39$ & $6.83 \pm 1.74$ & $12.91 \pm 1.01$ & $28.41 \pm 6.29$ & $0.19 \pm 0.01$ & $0.27 \pm 0.01$ \\
\hline Edges & $3.25 \pm 0.47$ & $7.57 \pm 1.67$ & $13.89 \pm 2.17$ & $31.86 \pm 8.75$ & $0.22 \pm 0.03$ & $0.28 \pm 0.07$ \\
\hline \multicolumn{7}{|l|}{ Quartz } \\
\hline Centre & $3.66 \pm 0.55$ & $5.96 \pm 01.22$ & $14.57 \pm 1.66$ & $20.26 \pm 3.07$ & $0.17 \pm 0.02$ & $0.20 \pm 0.01$ \\
\hline Corners & $4.06 \pm 0.95$ & $5.71 \pm 1.35$ & $16.29 \pm 3.92$ & $22.95 \pm 3.88$ & $0.18 \pm 0.01$ & $0.21 \pm 0.03$ \\
\hline Edges & $3.62 \pm 0.41$ & $5.97 \pm 1.48$ & $15.13 \pm 1.75$ & $22.53 \pm 5.5$ & $0.18 \pm 0.05$ & $0.22 \pm 0.03$ \\
\hline \multicolumn{7}{|l|}{ Feldspar } \\
\hline Centre & $2.90 \pm 0.56$ & $5.89 \pm 2.32$ & $11.60 \pm 1.61$ & $21.82 \pm 7.8$ & $0.17 \pm 0.02$ & $0.22 \pm 0.04$ \\
\hline Corners & $2.74 \pm 0.61$ & $5.97 \pm 1.10$ & $11.05 \pm 1.84$ & $22.32 \pm 4.9$ & $0.18 \pm 0.02$ & $0.24 \pm 0.04$ \\
\hline Edges & $2.98 \pm 0.48$ & $5.45 \pm 0.54$ & $12.29 \pm 1.94$ & $20.09 \pm 2.3$ & $0.17 \pm 0.02$ & $0.19 \pm 0.04$ \\
\hline
\end{tabular}

in roughness parameter Rvmax before and after SCT as measured on inter-granular contacts (Bt-Fs: biotite-feldspar; Bt-Qtz: biotitequartz; Qtz-Fs: quartz-feldspar) in the ZAR and ALP granites is given in Table 3.

As the table shows, the pre-SCT Rvmax and Smmax values were higher in ZAR than in ALP granite and these values rose in greater proportion in the former stone after the test. Before the SCI, the Rvmax values for the three mineral grain contacts were very similar in ZAR granite, although somewhat lower for Bt-Fs (mean 14.29 \pm $3.90 \mu \mathrm{m}$ ) than for Bt-Qtz (mean $14.74 \pm 4.34 \mu \mathrm{m}$ ) and Qtz-Fs (16.10 \pm $3.29 \mu \mathrm{m})$. The values were slightly higher on the corners and edges, particularly for the Qtz-Fs contact. After the SCI, the Rvmax values rose most in Bt-Fs (up by $18 \%$ in all, on average), followed by Bt-Qtz (10\%) and Qtz-Fs (2\%). The rises were greater in the centre of the specimens (especially in the case of Bt-Fs (average increase of 50\%)). In the Bt-Qtz and Qtz-Fs contacts, Rvmax declined slightly on specimen corners and edges. While prior to the SCT, the Bt-Qtz Smmax was substantially higher than the values for the other contacts in ZAR, after the test the values were very similar for all three types of contacts. The Bt-Fs and Qtz-Fs values declined slightly, by $1 \%$ and $5 \%$, respectively, while the dip was steeper for Bt-Qtz (33\%).

The pre-SCГ Rvmax values for the three mineral grain contacts were very similar in AIP granite, but slightly lower for Qtz-Fs (mean $8.17 \pm 1.55 \mu \mathrm{m}$ ) than for Bt-Fs (mean $10.58 \pm 2.31 \mu \mathrm{m}$ ) and Bt-
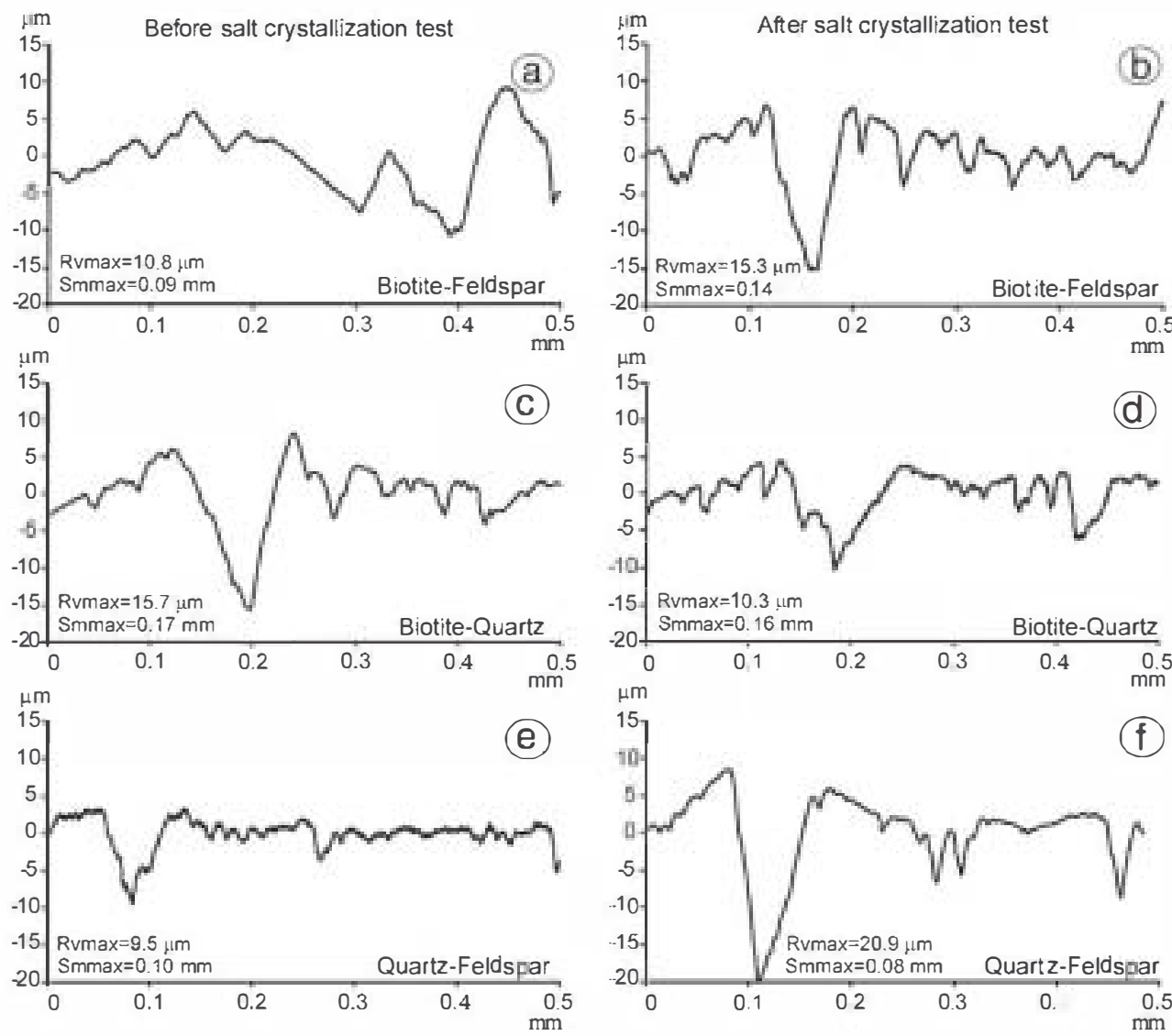

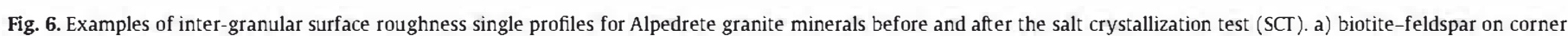

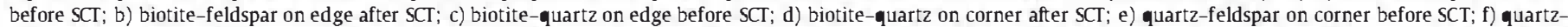

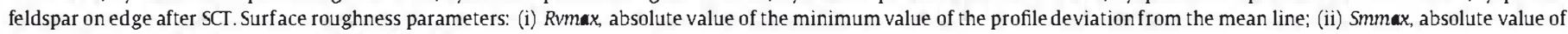
the maximum spacing between profile irregularities. 
Table 3

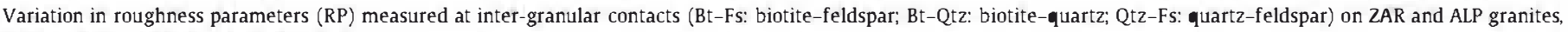
before and after salt crystallization test.

\begin{tabular}{|c|c|c|c|c|c|c|c|c|}
\hline \multirow{2}{*}{$\frac{\mathrm{RP}}{\text { Minerals }}$} & \multicolumn{2}{|c|}{$R v m a x(\mu \mathrm{m})$ ZAR } & \multicolumn{2}{|c|}{$R v \max (\mu \mathrm{m})$ ALP } & \multicolumn{2}{|c|}{$S \operatorname{mmax}[10,000 \%](\mathrm{mm})$ ZAR } & \multicolumn{2}{|c|}{$S m m a x[10,000 \%](\mathrm{mm})$ ALP } \\
\hline & Before & After & Before & After & Before & After & Before & After \\
\hline \multicolumn{9}{|l|}{$\mathrm{Bt}-\mathrm{Fs}$} \\
\hline Centre & $13.37 \pm 5.22$ & $19.55 \pm 4.94$ & $9.87 \pm 2.17$ & $11.89 \pm 1.58$ & $0.12 \pm 0.04$ & $0.12 \pm 0.03$ & $0.10 \pm 0.01$ & $0.10 \pm 0.02$ \\
\hline Corners & $13.17 \pm 2.28$ & $14.73 \pm 2.20$ & $11.76 \pm 1.56$ & $15.09 \pm 1.80$ & $0.12 \pm 0.30$ & $0.13 \pm 0.01$ & $0.14 \pm 0.04$ & $0.13 \pm 0.01$ \\
\hline Edges & $16.35 \pm 4.19$ & $15.70 \pm 2.82$ & $10.10 \pm 1.64$ & $14.55 \pm 3.54$ & $0.13 \pm 0.03$ & $0.13 \pm 0.03$ & $0.11 \pm 0.02$ & $0.13 \pm 0.02$ \\
\hline \multicolumn{9}{|l|}{$\mathrm{Bt}-\mathrm{Qtz}$} \\
\hline Centre & $14.06 \pm 3.15$ & $18.32 \pm 3.75$ & $12.35 \pm 4.18$ & $13.92 \pm 2.74$ & $0.12 \pm 0.05$ & $0.12 \pm 0.01$ & $0.12 \pm 0.04$ & $0.13 \pm 0.01$ \\
\hline Corners & $13.87 \pm 4.10$ & $14.80 \pm 4.23$ & $11.88 \pm 2.59$ & $12.63 \pm 2.75$ & $0.14 \pm 0.01$ & $0.12 \pm 0.03$ & $0.11 \pm 0.04$ & $0.13 \pm 0.02$ \\
\hline Edges & $16.30 \pm 5.78$ & $15.25 \pm 4.68$ & $11.61 \pm 1.98$ & $13.28 \pm 2.72$ & $0.13 \pm 0.03$ & $0.11 \pm 0.01$ & $0.10 \pm 0.01$ & $0.12 \pm 0.02$ \\
\hline \multicolumn{9}{|l|}{ Qtz-Fs } \\
\hline Centre & $15.09 \pm 3.71$ & $15.77 \pm 2.18$ & $9.16 \pm 1.77$ & $12.47 \pm 3.10$ & $0.13 \pm 0.03$ & $0.13 \pm 0.01$ & $0.10 \pm 0.02$ & $0.11 \pm 0.03$ \\
\hline Corners & $16.20 \pm 1.22$ & $15.23 \pm 2.16$ & $7.62 \pm 0.70$ & $13.53 \pm 3.28$ & $0.14 \pm 0.01$ & $0.12 \pm 0.03$ & $0.12 \pm 0.02$ & $0.10 \pm 0.04$ \\
\hline Edges & $17.30 \pm 4.93$ & $16.49 \pm 4.28$ & $7.72 \pm 2.16$ & $12.51 \pm 2.83$ & $0.14 \pm 0.05$ & $0.14 \pm 0.02$ & $0.10 \pm 0.03$ & $0.11 \pm 0.03$ \\
\hline
\end{tabular}

Qtz $(11.95 \pm 2.92 \mu \mathrm{m})$. Scant differences were found between the centre, corner and edge values. After the SCT, the Rvmax values rose in all the mineral grain contacts and at all specimen locations. The highest rise was recorded for Qtz-Fs (up by 60\% in all, on average), followed by Bt-Fs (31\%) and Qtz-Fs (11\%).

In ALP granite, Smmax before and after the SCT was very similar in the three mineral grain contacts, although it rose after the test, by $16 \%$ in $\mathrm{Bt}-\mathrm{Qtz}, 8 \%$ in Qtz-Fs and 7\% in Bt-Fs.

\subsection{Ultrasonic velocity}

ZAR and ALP granite ultrasound velocity results are given in Table 4. Measurements were taken along the three axes of the cubes and averaged to establish post-SCT rises or declines. Velocity declined in all ZAR samples after the SCT. The mean pre-SCT velocity in the selected samples, $3234 \mathrm{~m} / \mathrm{s}$, dropped to $2998 \mathrm{~m} / \mathrm{s}$ after the test, for an average decline of around 9\%. In ALP granite also, all the specimens had a higher velocity before ( $44 \%$ higher than in ZAR) than after the SCT. Before the SCT, the selected samples showed a mean velocity of $4670 \mathrm{~m} / \mathrm{s}$, which declined to $4446 \mathrm{~m} / \mathrm{s}$ after the test, i.e., by around $5 \%$.

\subsection{Mass variation, density and open porosity}

Table 5 shows the mass variation, density and open porosity values obtained by water absorption in vacuum, before and after the SCT.

The minus sign preceding the number in the weight variation (\%) column indicates weight loss, whereas the plus sign indicates weight gain. The weight gains shown in the weight variation column may have been due to premature completion of the salt rinsing process.

Table 4

Ultrasonic velocity values for Zar and ALP granites, before and after salt crystallization test (SCT).

\begin{tabular}{|c|c|c|c|c|c|c|}
\hline \multicolumn{2}{|c|}{$\begin{array}{l}\text { Granite } \\
\text { samples }\end{array}$} & \multirow[t]{2}{*}{ SCT } & \multirow{2}{*}{$\begin{array}{l}\text { Average } \\
\text { velocity for } 3 \\
\text { axes }(\mathrm{m} / \mathrm{s}) \\
\text { ZAR }\end{array}$} & \multirow[t]{2}{*}{$\begin{array}{l}\text { Variation } \\
\text { velocity } \\
\Delta V p(\%)\end{array}$} & \multirow{2}{*}{$\begin{array}{l}\text { Average } \\
\text { velocity for } 3 \\
\text { axes }(\mathrm{m} / \mathrm{s}) \\
\text { ALP }\end{array}$} & \multirow[t]{2}{*}{$\begin{array}{l}\text { Variatior } \\
\text { velocity } \\
\Delta V p(\%)\end{array}$} \\
\hline ZAR & ALP & & & & & \\
\hline 10 & 9 & $\begin{array}{l}\text { Before } \\
\text { After }\end{array}$ & $\begin{array}{l}3103 \\
3161\end{array}$ & -2 & $\begin{array}{l}4821 \\
4272\end{array}$ & 11 \\
\hline 16 & 15 & $\begin{array}{l}\text { Before } \\
\text { After }\end{array}$ & $\begin{array}{l}3116 \\
2808\end{array}$ & 10 & $\begin{array}{l}4761 \\
4535\end{array}$ & 5 \\
\hline 19 & 16 & $\begin{array}{l}\text { Before } \\
\text { After }\end{array}$ & $\begin{array}{l}3052 \\
2868\end{array}$ & 6 & $\begin{array}{l}4469 \\
4288\end{array}$ & 4 \\
\hline 26 & 17 & $\begin{array}{l}\text { Before } \\
\text { After }\end{array}$ & $\begin{array}{l}3174 \\
2957\end{array}$ & 7 & $\begin{array}{l}4615 \\
4373\end{array}$ & 5 \\
\hline 34 & 21 & $\begin{array}{l}\text { Before } \\
\text { After }\end{array}$ & $\begin{array}{l}3452 \\
3097\end{array}$ & 10 & $\begin{array}{l}4556 \\
4462\end{array}$ & 2 \\
\hline 35 & 28 & $\begin{array}{l}\text { Before } \\
\text { After }\end{array}$ & $\begin{array}{l}3506 \\
3097\end{array}$ & 12 & $\begin{array}{l}4798 \\
4743\end{array}$ & 1 \\
\hline
\end{tabular}

The mean variation in the mass of the six ZAR specimens tested was $-0.14 \%$. Such a slight variation after the first 15 cycles according to the standard UNE-EN 12370:1999 led to repetition of the test. After 30 cycles, a somewhat greater weight increment was found: $-0.85 \%$. The mean increment in the six ALP specimens after 30 cycles was $-0.18 \%$. The bulk density, before and after the SCT, was very similar in both granites. The average open porosity in the ZAR sample rose from $1.7 \%$ before to $1.9 \%$ after the SCT, for a $12 \%$ increase. At $0.9 \%$, the average pre-SCT open porosity was lower in the AIP than in the ZAR sample. It rose to $1 \%$ after the test, for an $11 \%$ increase. Mean water absorption in ZAR samples was $0.6 \%$ before and $0.7 \%$ after the SCT, while in ALP samples, the pre-SCT mean was $0.3 \%$ before and the post-mean $0.4 \%$. In other words, while open porosity was slightly higher in ZAR, the rise in water absorption was about the same in the two granites. Open porosity and water absorption increased in all the ZAR samples.

\subsection{Total porosity and pore size distribution (PSD) by MIP}

The MIP results for the granite samples are given in Table 6 and the PSD curves are shown in Fig. 7. Total porosity was observed to rise after the SCT in both Zarzalejo and Alpedrete granites: in ZAR, from $1.4 \%$ in the fresh sample to $2.11 \%$ in the weathered specimen; and in ALP, from $0.5 \%$ before to $1.01 \%$ after the test. The mean pore diameter was around $0.2 \mu \mathrm{m}$ in both fresh granites $(0.19 \mu \mathrm{m}$ in ALP and slightly higher, $0.24 \mu \mathrm{m}$, in ZAR). This value rose slightly in the ALP specimen (to $0.21 \mu \mathrm{m}$ ) after weathering. Mean pore diameter increased somewhat more in ZAR (to $0.31 \mu \mathrm{m}$ ) than in ALP.

The PSD results showed that neither of the stones exhibited pores below $0.01 \mu \mathrm{m}$ either before or after the test. Pores with diameters

Table 5

Mass variation, density and open porosity found by water absorption in vacuum, before and after the UNE-EN 12370:1999 salt crystallization test.

\begin{tabular}{|c|c|c|c|c|c|c|c|c|c|}
\hline \multirow{2}{*}{\multicolumn{2}{|c|}{ Samples }} & \multirow{2}{*}{$\begin{array}{l}\text { First } \\
\text { weight } \\
\text { variation } \\
(\%)\end{array}$} & \multirow{2}{*}{$\begin{array}{l}\text { Second } \\
\text { weight } \\
\text { variation } \\
(\%)\end{array}$} & \multicolumn{2}{|c|}{$\begin{array}{l}\text { Apparent } \\
\text { density } \\
\left(\mathrm{kg} / \mathrm{m}^{3}\right)\end{array}$} & \multicolumn{2}{|c|}{$\begin{array}{l}\text { Open } \\
\text { porosity } \\
(\%)\end{array}$} & \multicolumn{2}{|c|}{$\begin{array}{l}\text { Water } \\
\text { absorption } \\
(\%)\end{array}$} \\
\hline & & & & Before & After & Before & After & Before & After \\
\hline \multirow[t]{6}{*}{ ZAR } & 10 & -0.10 & -0.71 & 2656 & 2636 & 1.8 & 2.0 & 0.6 & 0.7 \\
\hline & 16 & -0.08 & -0.60 & 2643 & 2629 & 1.7 & 1.9 & 0.6 & 0.7 \\
\hline & 19 & -0.08 & -0.67 & 2624 & 2624 & 1.8 & 2.0 & 0.6 & 0.7 \\
\hline & 26 & -0.15 & -0.74 & 2641 & 2638 & 1.7 & 1.9 & 0.6 & 0.7 \\
\hline & 34 & -0.23 & -1.35 & 2646 & 2643 & 1.5 & 1.8 & 0.5 & 0.7 \\
\hline & 35 & -0.16 & -1.03 & 2689 & 2643 & 1.6 & 1.9 & 0.5 & 0.6 \\
\hline \multirow[t]{6}{*}{ ALP } & 9 & 0.03 & -0.17 & 2665 & 2660 & 0.8 & 1.0 & 0.3 & 0.4 \\
\hline & 15 & 0.05 & -0.15 & 2647 & 2660 & 0.9 & 1.0 & 0.4 & 0.4 \\
\hline & 16 & 0.05 & -0.28 & 2647 & 2650 & 1.0 & 1.2 & 0.4 & 0.4 \\
\hline & 17 & 0.05 & -0.18 & 2650 & 2666 & 0.8 & 1.0 & 0.3 & 0.4 \\
\hline & 21 & 0.04 & -0.17 & 2663 & 2659 & 0.8 & 1.0 & 0.3 & 0.3 \\
\hline & 28 & 0.04 & -0.14 & 2648 & 2665 & 0.8 & 0.8 & 0.3 & 0.3 \\
\hline
\end{tabular}


Table 6

Surface area, density, open porosity and pore size distribution of ZAR and ALP granite samples obtained by MIP before and after the salt crystallization test.

\begin{tabular}{|c|c|c|c|c|}
\hline \multirow[t]{2}{*}{ Granites } & \multicolumn{2}{|l|}{ ZAR } & \multicolumn{2}{|l|}{ ALP } \\
\hline & Before & After & Before & After \\
\hline Surface area $\left(\mathrm{m}^{2} / \mathrm{g}\right)$ & 0.088 & 0.104 & 0.039 & 0.074 \\
\hline Median pore diameter volume $\left(\mu \mathrm{m}^{3}\right)$ & 0.893 & 2.237 & 0.309 & 0.705 \\
\hline Mean pore diameter $(\mu \mathrm{m})$ & 0.24 & 0.31 & 0.19 & 0.21 \\
\hline Apparent density at $1.14 \mathrm{psia}\left(\mathrm{g} / \mathrm{cm}^{3}\right)$ & 2.65 & 2.62 & 2.67 & 2.65 \\
\hline Real density $\left(\mathrm{g} / \mathrm{cm}^{3}\right)$ & 2.69 & 2.68 & 2.68 & 2.67 \\
\hline Porosity $(\%)$ & 1.40 & 2.11 & 0.51 & 1.01 \\
\hline Micro<5 $\mu \mathrm{m}(\%)$ & 75.7 & 62 & 71.5 & 63.5 \\
\hline Macro $>5 \mu \mathrm{m}(\%)$ & 24.3 & 38 & 28.5 & 36.5 \\
\hline \multicolumn{5}{|l|}{ Pore size distribution } \\
\hline$<0.01 \mu \mathrm{m}(\%)$ & 0.00 & 0.00 & 0.00 & 0.00 \\
\hline $0.01-0.1 \mu \mathrm{m}(\%)$ & 12.68 & 9.76 & 15.43 & 15.57 \\
\hline $0.1-1 \mu \mathrm{m}(\%)$ & 39.15 & 29.34 & 53.50 & 43.39 \\
\hline $1-10 \mu \mathrm{m}(\%)$ & 27.17 & 31.06 & 7.20 & 5.64 \\
\hline $10-100 \mu \mathrm{m}(\%)$ & 6.15 & 6.37 & 8.86 & 11.79 \\
\hline$>100 \mu \mathrm{m} \mathrm{n \%})$ & 14.85 & 23.46 & 15.01 & 23.61 \\
\hline
\end{tabular}

ranging from 0.01 to $0.1 \mu \mathrm{m}$ prevailed in both ZAR and ALP, although the percentage declined slightly after salt weathering in both granites (in the AlP sample, however, the percentage of 0.01 to $0.03-\mu \mathrm{m}$ pores rose and the percentage in the 0.03 to $0.05-\mu m$ range declined). In ZAR, the number of pores from 0.1 to $1 \mu \mathrm{m}$ and 1 to $3 \mu \mathrm{m}$ declined slightly, while the percentage of those measuring from 3 to $10 \mu \mathrm{m}$ increased. Moreover, pores with diameters between 5 and $10 \mu \mathrm{m}$, non-existent in the fresh samples, appeared in the weathered ZAR specimens. The percentage of pores with diameters over $100 \mu \mathrm{m}$ also rose $(23.6 \%)$.

The percentage of these over $100 \mu \mathrm{m}$ pores grew in ALP as well, along with pores between 0.5 and $2 \mu \mathrm{m}$, while pores with diameters ranging from 0.1 to $0.5 \mu \mathrm{m}$ declined in number and no pores were detected in the $2-10 \mu \mathrm{m}$ range. The proportion of pores in the 0.01$0.05 \mu \mathrm{m}$ and $10-100 \mu \mathrm{m}$ ranges was similar in both fresh and
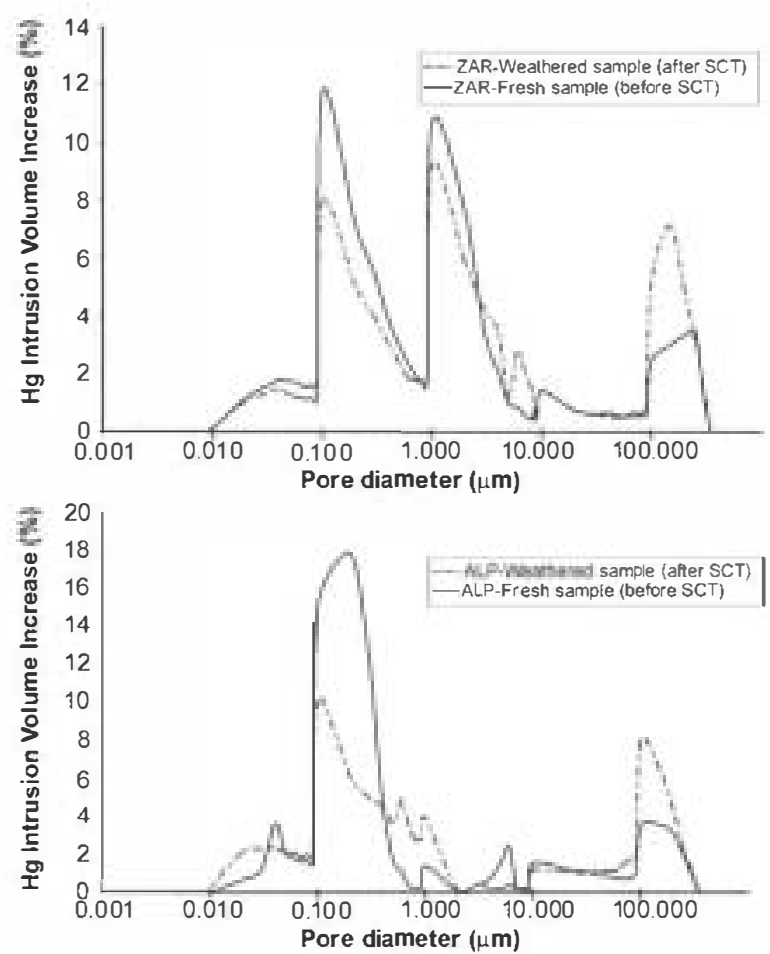

Fig. 7. Open porosity and pore size distribution determined by MIP for ZAR and ALP granites. weathered ALP and ZAR specimens. The main difference was found in the $0.5-10 \mu \mathrm{m}$ range.

Before the SCT, ALP granite had a high real density $\left(2.68 \mathrm{~g} / \mathrm{cm}^{3}\right)$ and low total porosity (0.5\%). The latter is defined to be the sum of the pores $<5 \mu \mathrm{m}(71.5 \%)$ and the pores $>5 \mu \mathrm{m}(28.5 \%)$. The PSD was found to be bimodal, with one mode in the $0.1-0.5 \mu \mathrm{m}$ interval (over $50 \%$ of the total porosity in the sample) and the other in the $>100 \mu \mathrm{m}$ interval. After the SCГ, real density declined slightly (to $2.67 \mathrm{~g} / \mathrm{cm}^{3}$ ), while total porosity increased considerably (to 1.01\%).

Before the SCГ, ZAR granite had a similar real density $(2.69 \mathrm{~g} / \mathrm{ml})$ and a higher total porosity (1.4\%) than the Alpedrete stone. The percentage of $<5 \mu \mathrm{m}$ pores (75.7\%) trebled the $>5 \mu \mathrm{m}$ value $(24.3 \%$ ). Pore size was concentrated primarily in three intervals: $0.1-1 \mu \mathrm{m}$ (over 39\% of total porosity), 1-5 $\mu \mathrm{m}$ (over 25\%) and $>100 \mu \mathrm{m}$. After SCГ weathering, real density declined slightly in ZAR (from 2.69 to $2.68 \mathrm{~g} / \mathrm{cm}^{3}$ ), while total porosity rose somewhat (from $1.4 \%$ to $2.1 \%$ ). The proportion of pores $>5 \mu \mathrm{m}$ grew (to one third of the initial total porosity), with the major share (23.5\%) measuring $>100 \mu \mathrm{m}$.

The three other parameters determined with MIP were specific surface $\left(\mathrm{m}^{2} / \mathrm{g}\right)$, pore volume $\left(\mu \mathrm{m}^{3}\right)$ and mean pore diameter $(\mu \mathrm{m})$ (Table 6). Both the initial values of these parameters and their pattern of change after the SC $\Gamma$ differed in the two granites.

After the SCT, ZAR pore diameter and specific surface grew slightly (from $0.241 \mu \mathrm{m}$ to $0.311 \mu \mathrm{m}$ and from $0.088 \mathrm{~m}^{2} / \mathrm{g}$ to $0.104 \mathrm{~m}^{2} / \mathrm{g}$, respectively), while pore volume rose to over double the initial value (from $0.893 \mu \mathrm{m}^{3}$ to $2.237 \mu \mathrm{m}^{3}$ ). In ALP, in turn, pore diameter increased slightly (from $0.193 \mu \mathrm{m}$ to $0.206 \mu \mathrm{m}$ ), but pore volume and specific surface jumped to double the initial values (from $0.309 \mu \mathrm{m}^{3}$ to $0.705 \mu \mathrm{m}^{3}$ and $0.039 \mathrm{~m}^{2} / \mathrm{g}$ to $0.074 \mathrm{~m}^{2} / \mathrm{g}$, respectively).

\section{Discussion}

\subsection{Intra-granular and inter-granular surface roughness}

According to the results, in fresh (pre-SCT) ZAR samples, biotite had the lowest $R a$ values (defined as curve deviations from the mean line), followed by feldspar and then quartz, (Fig. 5 and Table 1). After the SCr, central, comer and edge quartz $R a$, and central feldspar $R a$ increased by about $50 \%$ of the initial (pre-SC ) value. The Ra rose by more than double for biotite on specimen centres, comers and edges and feldspar on the corners and edges. The steep rises in roughness parameter $R a$ values for biotite after the SC $\Gamma$ were due the opening of mica cleavage planes (Chen et al., 2000; Alonso etal., 2008). Parameter $R z$ followed the same pattem as $R a$ in both AIP and ZAR. Biotite $R a$ and $R z$ roughness measurements were observed to also depend on the orientation of the mineral. When measurements were taken on the basal planes, the $R a$ and $R z$ values were much lower; this would explain the higher standard deviation for this mineral, particularly for post-SCT Rz. However, biotite exhibited no prevalent orientation in these granites and the number of measurements ( 48 for each type of granite: four in the centre, four at the corners and four on the edges of each of four specimens) was regarded to be large enough to accommodate the possible differences in orientation in the samples analyzed.

In feldspars, significant variation was observed in the surface roughness of fresh alkali feldspar grains of the same size and from the same source rock, with some relatively high values denoting grains rich in patch perthite and lower values reflecting the presence of grains in which cryptoperthite and lamellar microperthite prevailed (Lee and Parsons, 1995). Surface roughness values obtained for freshly ground and washed alkali feldspar as the ratio of the specific surface (obtained by the BET gas adsorption technique) to the geometric area (obtained by direct measurements of grain size and shape) ranged from 3.0 to 10.4 (Holdren and Speyer, 1985, 1987). In a number of naturally weathered alkali feldspars from soils, by comparison, this parameter ranged from 83 to 653. The value of 2 obtained under atomic force microscopy (Blum, 1994), in turn, indicated that much of 
the additional specific surface was internal to the crystals and that the irregularity of cleavage surfaces may have made a significant contribution to surface roughness. This provides a further explanation for the fairly high standard deviation found in the intra-granular surface roughness values, particularly the post-SCT $R z$, for feldspar grains in both types of granites (Tables 1 and 2).

While the location of feldspar and quartz on specimen surfaces had no effect on $\mathrm{Sm}$ values, this parameter did vary with location for biotite, which showed higher values on the corners and edges after the SCT, especially in ZAR. The higher $S m$ values (defined to be the mean spacing between profile irregularities) for biotite explain and quantify the post-SCT opening of biotite basal planes. The Sm values for all three mineral grains were slightly higher in ZAR than ALP. The highest values were recorded for biotite, both before and after the SCT, with larger post-test increases at corners and edges. The lowest values and smallest rise in $\mathrm{Sm}$ were found for quartz, with feldspar in an intermediate position.

The effect of mineral location in more (corners and edges) or less (centre) exposed areas was visible in ZAR granite after the SCT. This was especially the case for feldspar, as, while in biotite the Sm rose by more than double and in quartz by around $50 \%$, regardless of location, in corner and edge feldspar it grew by more than double, but by only around half of the initial value when the mineral was located in the centre of the sample. On the contrary, specimen cutting with a diamond blade saw would appear to have little effect on roughness parameters (in the case of intra-granular study), in light of the scant difference observed between the central and corner/edge values in the fresh specimens (before the SCT).

In AlP granite before the SCT, feldspar had the lowest $R a$ values, followed by biotite and then quartz (Table 2). After weathering (SCT), the value of this parameter nearly doubled in feldspar regardless of location and grew by about $50 \%$ in central, and more than $100 \%$ in corner and edge, biotite. As in ZAR, quartz Ra grew in ALP (after the $\mathrm{SCT}$ ) by less than $50 \%$ regardless of the location of the mineral.

Initially, before the SCT, the $R z$ roughness parameter was higher in the ZAR than in the AIP samples with respect to all selected mineral grains at every location (by $30 \%$ in feldspar, $23 \%$ in biotite and $50 \%$ in quartz). After the test, values increased at a similar rate in the two samples: quartz rose by around 50\% (slightly less in ALP); the figure for biotite was double the initial value at all locations in ZAR granite, and more than double at corners and edges in the ALP sample; in feldspar the increase was $50 \%$ in the centre and more or less $100 \%$ at the corners and edges of the ZAR granite specimens, and nearly double at all locations in the ALP specimens. In other words, the $R z$ parameter followed the same pattern as $R a$ in both ALP and ZAR

Before the SCT, the values of roughness parameters $R a, R z$ and $S m$ were higher in the ZAR than in the ALP samples, particularly as regards quartz grains (whose $R a$ showed a $64 \%$ increase). In feldspar the difference was on the order of $35 \%$ while in biotite of only $16 \%$. The average post-SCT increase in $R a$ was also greater in the ZAR sample, especially for biotite (which initially had the lowest $R a$ value), whose values grew by more than double regardless of its location. In the AlP sample, in turn, biotite $R a$ rose by more than double at the corners and edges and by around 50\% in the centre of the sample. In ZAR, the postSCT value for feldspar was double the initial value at the corners and edges only, with the figure for the central grains increasing by $20 \%$. In the ALP samples feldspar weathered evenly (with increases of approximately $100 \%$ ) regardless of its location. In both the ZAR and AlP specimens, the increase in quartz grain roughness $(R a)$ was around $50 \%$ of the initial value, regardless of location.

In both granites, therefore, location influenced post-SCT mineral roughness parameters. Specimen cutting with a diamond blade saw initially appeared to have little effect on $R a$, however, in light of the scant difference between the central and corner/edge values in the fresh specimens (before the SCT), with the exception of quartz grains located at the corners, which exhibited higher values. In ZAR before the SCT, the value of $R z$ was very similar in the centre and on the edges and corners for all the minerals, except for corner biotite and quartz, which exhibited higher values. These results indicate that the diamond blade saw cut did affect this parameter, in quartz grains more than the other two minerals, in light of its higher $R a$ and $R z$ values on edges and corners than in the centre in the fresh (pre-SCT) samples. Initial sample surface roughness was caused by the saw and depended on the blade used. While this did not affect the present results, which compare roughness values before and after the SCT, it may have had an impact on the differential behaviour of the minerals, depending on their hardness or abrasion resistance. The higher postSCT corner and edge SR values in both granites (compared to the centre values) may be explained by their greater exposure to salt solution penetration and alteration due to saw cutting, and by the fact that volume expansion during salt crystallization is less confined in these areas.

Intra-granular surface roughness values were higher and rose more after the SCT than the inter-granular surface roughness values, in both granites (Figs. 5 and 6 and Tables 1-3). Inter-granular measurements showed that ZAR had higher pre-SCT Rvmax values, and steeper rises after the test, but in the centre of the specimens only, for the value of this parameter actually declined at the corners and edges, particularly in the Qtz-Fs contacts. In ALP granite, Rvmax rose more for contacts located at the corners and edges. Bt-Fs in ZAR and Qtz-Fs in ALP were the mineral contacts most affected by the increase in SR. These findings prove that feldspar and its grain contacts are the weakest areas and therefore most prone to decay.

No differences were observed in the measurements taken in the inter-granular contacts at the centre, corners or edges of the pre-SCT ALP specimens: in other words, these contacts were not affected by cutting. The post-SCR increase in SR values was higher in specimen corners and edges than in the centre.

The pre-SCT values in ZAR. by contrast, did reveal location-based differences, particularly for the Qtz-Fs contact, where the higher values recorded on specimen corners and edges denoted the effect of cutting, similar to the effect observed for Qtz in the intra-granular SR study. Such alterations could impact the quartz surrounding minerals and generate trans-granular fissures (Fig. 4a).

In post-SCT ZAR, the inter-granular SR values declined slightly at corners and edges. The explanation for this finding is that the ZAR specimens were visually eroded in these areas: the sharp, smooth corners and edges in pre-SCT samples gave way to rounder, rougher surfaces, as these were the most severely weathered parts of the specimens, particularly in this granite. Dimensional loss in these visibly weathered parts of the stone was confirmed by the $0.6 \%$ to $1.4 \%$ weight loss detected (Table 5) after the SCT. This in turn would explain why, on the edges and corners where the outer-most surface of the granite had worn away, the maximum depth and width of the valleys between mineral grains (Rvmax and Smmax, respectively) were shallower and narrower, rather than deeper and wider, than in both ALP granite and the centre of the ZAR specimens.

\subsection{Relationship between roughness and other results}

\subsubsection{PLOM and ESEM}

Further to the study of thin sections, the SCT caused barely any physical or chemical alterations in the rock-forming minerals in the Alpedrete and Zarzalejo monzogranites. Cracks and fissures were also difficult to detect, particularly when located between minerals (inter-granular cracks). Even intra-granular (cracks inside a mineral) and trans-granular (affecting more than one mineral) cracks may be hard to see (Sousa et al., 2005).

The polarized light optical microscopic (PLOM) and environmental scanning electron microscopic (ESEM) findings in the samples before SCT, however, revealed natural dissolution-corrosion processes in feldspar due to plagioclase seritization. These weathered areas were 
more readily penetrated by salt solutions, which may explain the concomitant post-SCT rise in porosity observed in water absorption and MIP analyses. Most physical properties of granites for ornamental use are known to be affected primarily by voids in the "pristine rock", for weathering processes are known to widen microfractures and therefore the number of pore-shaped voids, particularly in feldspars (Sousa et al., 2005). Plagioclase and feldspar alteration on granitic stocks from Southern Iberian Massif (Spain), studied by JiménezEspinosa et al. (2007), appears to result from dissolution especially along cleavage and fracture planes.

Greater intra-granular surface roughness ( $R a$ and $R z$ ), especially in feldspar grains, may be due to salt solution penetration and crystallization during accelerated ageing that affect almost the entire mineral grain. Dislocations in alkali feldspars may act as pathways for the ingress of relevant amounts of fluid into feldspar crystals (Lee and Parsons, 1995). Experiments conducted by these authors on alkali feldspars etched with HF acid showed that patch perthites (irregular, microporous microcline and albite intergrowths) dissolved. The pits enlarged by etching subsequently merged, giving rise to a highly porous, honeycomb texture. The heavily pitted areas were believed to be albite-rich and the areas with fewer pits to constitute K-feldspars.

Sousa et al. (2005), using a combination of PLOM and fluorescence microscopy, identified intra-granular fissures or cracks to be the most frequent type of fissures in naturally weathered granites, accounting for $63 \%$ to $82 \%$ of all the cracks observed on two different types of granites with a medium to coarse grain size. This may explain why the post-SCT increase (Tables 1 and 2) in intra-granular surface roughness was higher than the rise in inter-granular roughness (Table 3). These authors also found that inter-granular cracks constituted less than one third of all microfractures in all the granites studied and were predominantly located at quartz-feldspar boundaries. These findings concur with the present ESEM findings (Fig. 4a), as well as intergranular surface roughness measurements, where the highest Rvmax values were found between quartz and feldspar grains in ALP granite (Table 3), and biotite and feldspar grains in ZAR granite.

According to intra-granular measurements, biotite underwent the greatest increase in roughness after the SCT. That, and the fact that biotite grain size is larger and less uniform in ZAR $(2-4 \mathrm{~mm})$ than in ALP (around $2 \mathrm{~mm}$ ), might explain the higher values for roughness parameters $R a$ and $R z$ and therefore the greater decay in the former stone. It may also be the reason why $R a$ grew at the same rate (more than double) regardless of where biotite grains were located on the ZAR specimen surface, but differentially depending on position in the ALP sample ( $50 \%$ in the centre and $100 \%$ on the corners and edges). A study conducted by Matias and Alves (2001) on stones in monuments at Braga, in north-western Portugal, showed that the decay patterns of biotite-rich, medium- to fine-grained granite were associated with quarry weathering, the presence of heterogeneous elements (enclaves and phenocrysts) and grain size variations. They also found that granular disintegration-mediated decay was more intense in coarser grained stones. Granular disintegration consists in grainby-grain disaggregation along grain boundaries, cleavages and minute fractures, particularly those in the vicinity of altered biotite grains. Biotite-rich rocks abrade most readily because they weather most readily. Granite has been observed to disintegrate due to biotite expansion during weathering. Laboratory and field studies have shown that $\mathrm{K}$-ion leaching from the crystal structure and the addition of water and other ions causes biotite expansion due to splitting along basal cleavages, exposing additional surface area to chemical attack (Bradley, 1970; Helmi, 1985). Dissolution and expansion of secondary mineral phases along cleavage planes and grain boundaries controlled deterioration of the microfabric by causing transgranular cracking and the opening of grain boundaries ultimately causing disintegration of the rock (Curran et al., 2002).

Biotite expansion is a physical weathering process: feldspars are affected by chemical weathering, namely salt solution-induced rises in pH (Schiavon et al., 1995). Nonetheless, the presence of potassium feldspar and plagioclases in micro-fragments of Zarzalejo granite (Fig. 4c and d) revealed by post-SCT EDS chemical analysis showed that salt crystallization caused physical desegregation of these minerals. Physical weathering might also have been responsible for the observed increase in surface roughness. Salt crystallization pressure generates tensile stress on pore surfaces, leading to microcracking in the form of the initiation and propagation of new, or the extension and widening of existing, microcracks and pores, which cause rock disintegration, detachment and fracturing (Scherer, 1999; Nicholson, 2001; Scherer et al., 2001).

Biotite minerals are also related to the increase in porosity due to the salt solution penetration- and crystallization-induced opening of basal plane layers, as discussed above. Gypsum crystallization along mica basal cleavage planes and extensive feldspar kaolinization has been observed in granite surfaces on a church at La Coruña, in northwestern Spain (Schiavon, 2007), where such stone is also frequently used as a building material. The opening of biotite planes during the salt crystallization test (Fig. $4 \mathrm{a}$ and b) may also generate stress in the crystals, resulting in the development of fissures running across them (trans-granular fissures). The inter-granular contact between biotite and quartz, for instance, constitutes a boundary between materials with different atomic lattices, types of bond, strength and E-modulus, resulting in different microfracture propagation patterns (Moore and Lockner, 1995). These authors observed that microcracks in underformed rock and in the far-field region of the laboratory sample were concentrated within and along the edges of quartz crystals, but near the shear fracture they were somewhat more abundant within $\mathrm{K}$ feldspar crystals.

On the other hand, quartz grains might also be related to the increase in open porosity, pursuant to the cracking and widening of pre-existing fissures observed under the polarized light optical microscope but not detected during roughness measurements because the dimensions fall outside the detection range. This led to a smaller increase in the roughness parameter for this mineral because the readings were taken on the smooth, solid areas of the grains.

\subsubsection{US, open porosity and water absorption}

As noted above, salt crystallization pressure generates tensile stress across pore surfaces (Scherer, 1999) and microcracking, with the initiation and propagation of new cracks or the extension and widening of existing microcracks and pores. Determination of open or free porosity on granite from Oporto (Portugal) is considered by Begonha and Sequeira Braga (2002) as the property most strongly influenced by weathering.

Post-SCT declines in ultrasonic velocity have been attributed to this widening of existing cracks or the appearance of new cracks (Alonso et al., 2008) and the development of new (Ruiz de Argandoña et al., 1988; Suzuki et al., 1995) and the widening of existing (Suzuki et al., 1998) inter-granular cracks. The greater post-SCT decline in velocity observed for ZAR than ALP granite denotes the development of more fissures in the former. This is consistent with the initially higher open porosity and water absorption values in ZAR specimens and the steeper rise in these parameters after SCT. An inverse relationship between ultrasound velocity and open porosity has been reported by other authors for different stones (Calleja et al., 1989; Jermy and Bell, 1998; Marques and Vargas, 1998; Sousa et al., 2005). In ZAR granite, the post-SCT cracks and intra-granular and transgranular fissures observed in quartz and feldspars under ESEM and the opening of biotite basal planes detected with roughness measurements (Sm) and observed under ESEM (Fig. 4a), can be related to this decline in ultrasound velocity and rise in open porosity.

\subsubsection{MIP}

Mercury intrusion porosimetry (MIP) was performed on 1-cm $\odot \times 3-$ cm cylinders removed from the specimen surface, while open porosity 
was measured by water absorption in vacuum on 5-cm cube specimens. These differences and the higher pressures involved in MIP explain the variations in both the pre- and post-SCT porosity data.

In both ZAR and ALP, pores ranging in diameter from 0.01 to $0.1 \mu \mathrm{m}$ were the most abundant, but their percentage declined slightly with salt weathering (Fig. 7). This concurs with Winkler (1997) that pores with diameters of under $0.1 \mu \mathrm{m}$ are scantly affected by decay because they cannot absorb moisture and that the weathering process primarily affects larger pores with the gradual break-up of the grains, much the same as in crystallization tests.

The appearance of $0.5-2 \mu \mathrm{m}$ pores in weathered ALP samples may possibly be attributed to the opening of intra-granular pores and fissures, while the rise in the percentage of pores of over $100 \mu \mathrm{m}$ in both granites might be the outcome of the development and widening of inter-granular and trans-granular fissures (as observed under ESEM). Mosquera et al. (2000) using MIP, obtained clearly bimodal pore size distributions for granite (as observed here for ALP) and defined a group of macrofissures as trans-granular fissures and similarly sized microfissures as inter- and intra-granular fissures.

The stress generated by salts in pores leads to greater pore size and porosity and a decline in rock strength (Winkler, 1997; Benavente et al., 1999; Nicholson, 2001). The percentage of $1-3-\mu \mathrm{m}$ pores

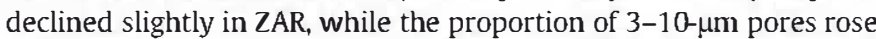
and a new group of pores, with diameters of 5 to $10 \mu \mathrm{m}$, appeared (a development that may be related to the existence of intra-granular pores and fissures). This increase in post-SCT microporosity can be associated with the rise in biotite and feldspar surface roughness.

In ZAR the percentage of pores $>5 \mu \mathrm{m}$ grew (accounting for one third of the initial porosity) after the SCT, with a prevalence of the over $100 \mu \mathrm{m}$ size class (23.5\%), perhaps as a result of the generation of inter- and trans-granular fissures. Macroporosity may be associated with intra-granular cracking in quartz grains and the trans-granular cracks propagated to surrounding minerals.

Variations in specific surface $\left(\mathrm{m}^{2} / g\right)$, pore volume $\left(\mu \mathrm{m}^{3}\right)$ and mean pore diameter $(\mu \mathrm{m})$ denote changes in the size and morphology of the pores (Meyer et al., 1994).

The post-SCT growth in ZAR pore diameter and specific surface (from $0.241 \mu \mathrm{m}$ to $0.311 \mu \mathrm{m}$ and from $0.088 \mathrm{~m}^{2} / \mathrm{g}$ to $0.104 \mathrm{~m}^{2} / \mathrm{g}$, respectively) and the rise in pore volume to over double the initial value (from $0.893 \mu \mathrm{m}^{3}$ to $2.237 \mu \mathrm{m}^{3}$ ) suggest a change in pore morphology to larger and possibly interconnected pores. In ALP, in turn, pore diameter increased slightly (from $0.193 \mu \mathrm{m}$ to $0.206 \mu \mathrm{m}$ ), but pore volume and specific surface jumped to double the initial values (from $0.309 \mu \mathrm{m}^{3}$ to $0.705 \mu \mathrm{m}^{3}$ and $0.039 \mathrm{~m}^{2} / \mathrm{g}$ to $0.074 \mathrm{~m}^{2} / \mathrm{g}$, respectively). These findings infer that the pores were smaller and more irregularly shaped than in ZAR and perhaps also interconnected.

Using resin impregnation and SEM, Lee and Parsons (1995) observed: a three-dimensional network of corroded dislocations extending $>15 \mu \mathrm{m}$ beneath the surface of slightly weathered alkali feldspars; submillimetre to millimetre sized alkali feldspar micropores with some turbid regions (comprising orthoclase and albite-rich feldspar intergrowths), typically containing 0.65-0.70 angular micropores $/ \mu m^{2}$, for microporosities of approximately $1-2 \%$; patch perthites (irregular microporous microcline and albite intergrowths) characterized by large irregular corrosion pits and continuous channels delineating subgrain boundaries; and on microperthite cleavage surface 001, the enlargement of initially trapezoidal or hexagonal corrosion pits into near-equilateral triangles.

Sousa et al. (2005) observed that since salt crystallization is conditioned by voids or porosity, the damage caused by ageing tests in granites with open porosities of under $1.5 \%$ was practically nil after 100 salt crystallization cycles; with increasing porosity, however, material loss grew to significant levels. This would explain, in part, why ZAR (with an open porosity of $1.4 \%$ ) was more weathered after SCT than ALP (with an open porosity of $0.5 \%$ ) and why its intragranular roughness was higher but its inter-granular roughness at the corners and edges was lower. Walker (1990) and Walter (1991) found that fresh unweathered alkali feldspars had $0.25-4.75$ vol.\% porosity (average 1.45\%) and that their micropores were often connected. The foregoing means that in ALP and ZAR granites, feldspar plays a significant role in salt solution absorption, while salt crystallization in its pores leads to greater porosity, crack and fissure development, the breakdown of mineral grains and mass loss.

\section{Conclusions}

The natural weathering in Zarzalejo (ZAR) and Alpedrete (ALP) granites from Madrid, Spain, observable under polarized light optical (PLOM) and environmental scanning electron (ESEM) microscopes, mainly involves feldspar grains. Before the sodium sulphate salt crystallization test (SCT), the ultrasound velocity (UV) values were lower, while open porosity, water absorption and surface roughness (SR) values were higher in ZAR than ALP granite. While post-SCT physical-chemical weathering detected under PLOM and ESEM was scant in both granites, the mean decline in US, the rise in SR parameters and weight loss were also greater in ZAR than ALP.

Surface roughness measurement of mineral grains in granite stones is a very useful, in situ, non-destructive technique for quantifying salt crystallization-mediated physical and chemical weathering, as well as decay in and durability of this type of stone, typically used in historic buildings.

1. The intra-granular SR study showed that the pre-SCT Ra, Rz and Sm values were higher in ZAR than in ALP and rose more in the former after the test. Bt and Fs were the minerals with the lowest initial values in ZAR and ALP, respectively. After the SCT, the $R a$ and $R z$ for Bt rose by more than double regardless of its location on ZAR specimens, as well as on the corners and edges of ALP specimens, but only by $50 \%$ at centre ALP locations. The $R a$ and $R z$ values for Fs doubled at all locations in ALP specimens but only on the corners and edges of ZAR specimens, where the values for centrally located Fs grew by $50 \%$. Qtz was the mineral with the highest initial $R a$ and $R z$ values in both granites, but since they only rose by $50 \%$ after the SCT regardless of the location of the grains, the final values were similar to the Bt and Fs values.

2. The intra-granular study showed that Bt and Fs were the minerals most affected by the increase in SR in both granites. According to the inter-granular study, Bt-Fs in ZAR, and Qtz-Fs in ALP were the mineral contacts most affected by the increase in SR. The initial values and the post-SCT increases were higher on specimen corners and edges. In other words, feldspar and biotite and their inter-granular contacts were found to be the weakest and hence most decay-prone areas.

3. Physical weathering caused by salt crystallization and the opening of cleavage planes with concomitant increases in microporosity were observed in $\mathrm{Bt}$, along with intra-granular fissures that developed into trans-granular fissures. The physical-chemical weathering due to salt solution reactions and crystallization observed in Fs led to increases in microporosity and intra-, interand trans-granular fissures. The physical weathering exhibited by Qtz, induced primarily by sawing and salt crystallization, intensified inter-granular fissuring and prompted the appearance of trans-granular fissures. The initial SR parameters were generally higher and rose more steeply after SCT at the corners and around the edges of the specimens.

4. While behaviour was similar in the two types of granite, post SCT variations in the parameters studied were greater in ZAR. The larger biotite and feldspar grain sizes in this granite and their concomitantly larger specific surface allowed greater salt solution penetration and crystallization between biotite cleavage planes and inside natural feldspar micropores. This Zarzalejo variety was found to be a less durable, more decay-prone granite than ALP. 
While stylus instrument, 2D profilometry and contact gauge measurement of surface roughness is more time-consuming and less precise than modern surface roughness instrument techniques, it is less expensive and a sufficiently accurate, highly useful and generally affordable method of quantifying material decay and durability.

This study allows researchers to understand the physical changes that occur in bedrock due to chemical and physical salt weathering processes. These are mainly changes in porosity and density of the samples with increased weathering, which are similar to the processes important for the development of soils. It leads to the changing hydrologic conditions that result in increased rate of weathering with time due to intrinsic changes in the properties of the exposed bedrock.

\section{Acknowledgements}

This study was funded by the Government of the Community of Madrid under the MATERNAS project (Durability and conservation of traditional natural materials in heritage architecture) (MATERNAS CM 0505/MAT/0094) and the Spanish Ministry of Science and Innovation as part of the Consolider-Ingenio 2010 programme (CSD2007-0058). Thank you to the JAE-Doc CSIC contract for supporting P. López-Arce to develop this work. The authors are grateful to Laura Tormo of the Natural Science Museum (CSIC) for providing the ESEM photographs and analyses. Special thanks go to Inmaculada Ruiz and Iván Serrano, IGE (Institute of Economic Geology) petrophysics laboratory technicians, for their work, suggestions, ideas, and support. We also thank Margaret Clark for the English review of the manuscript, and to Nick Schiavon for his comments and for having greatly improved the manuscript. We also appreciate the help of two anonymous referees for the reviewing process that also has improved the present research.

\section{References}

Akesson, U., Stigh, J., Lindqvist, J.E., Göransson, M., 2003. The influence of foliation on the fragility of granitic rocks, image analysis and quantitative microscopy. Engineering Geology 68 (3-4), 275-288.

Alonso, F.J., Vázquez, P., Esbert, R., Ordaz, J., 2008. Ornamental granite durability: evaluation of damage caused by salt crystallization. Materiales de Construccion 58 (289-290), 191-201.

Bea, F., Villaseca, C., Bellido, F., 2004. El batolito de Ávila (Sistema Central Español). In: Vera, J.A. (Ed.), Geología de España. Sociedad Geológica de España y el Instituto Geológico y Minero de España, Madrid, Spain, pp. 101-110

Begonha, A., Sequeira Braga, M.A., 2002. Weathering of the Oportogranite: geotechnical and physical properties. Catena 49, 57-76.

Benavente, D., García del Cura, M.A, Fort, R., Ordóñez, S., 1999. Thermodynamic modelling of changes induced by salt pressure crystallisation in porous media of stone. Journal of Crystal Growth 204 (1-2), 168-178.

Blateyron, F., 2000. 3D parameters and new filtration techniques. 7 pp. http://www. digitalsurf.fr/download/jspe2006.pdf (last access 15th December 2008).

Blum, A.E., Yund, R.A. Iasaga, A.C., 1990. The effect of dislocation density on the dissolution rate of quartz. Geochimica et Cosmochimica Acta 54 (2), 283-297.

Blum, A.E., 1994. Feldspars in weathering. In: Parsons, I. (Ed.), Feldspars and Their Reactions. Kluwer, Dordrecht, pp. 595-630.

Bradley, W.C., 1970. Effect of weathering on abrasion of granitic gravel, Colorado River (Texas). Geological Society of America Bulletin 81, 61-80.

Calleja, L., Montoto, M., Pérez García, B., Suárez del Río, L.M., Martínez Hernando, A., Menéndez Villar, B., 1989. An ultrasonic method to analyze the progress of weathering during cyclic salt crystallization laboratory tests. 1st International Symposium on the Conservation of Monuments in the Mediterranean Basin. Grafo Edizioni, Bari (Italy), pp. 313-318.

Chen, J., Blume, H.P., Beyer, L, 2000. Weathering of rocks induced by lichen colonizationa review. Catena 39, 121-146.

Curran, J., Smith, B., Warke, P., 2002. Weathering of igneous rocks during shallow burial in an upland peat environment: observations from the Bronze Age Copney Stone Circle Complex, Northern Ireland. Catena 49, 139-155.

DIN EN ISO 3274:1996. Geometrical Product Specifications (GPS) - Surface texture: Profile method - Nominal characteristics of contact (stylus) instruments.

Doehne, E., 2002. Salt weathering: a selective review. Geological Society, Iondon, Special Publications 205, 51-64.

Fort, R., Mingarro, F., López de Azona, M.C., 1996. Petrología de los materiales de construcción del Palacio Real de Madrid. Geogaceta 20 (5), 1236-1239.

Fort, R., Fernández-Revuelta, B., Varas, M.J. Álvarez, de Buergo, M., Taborda-Duarte, M., 2008. Influencia de la anisotropía en la durabilidad de las dolomías Cretácicas de la Comunidad de Madrid frente a la cristalización de sales/lnfluence of anisotropy on the durability of Madrid-region Cretaceous dolostone exposed to salt crystallization processes. Materiales de Construccion 58 (289-290), 161-178.
García del Cura, M.A., Benavente, D., Bernabéu, A., Martínez-Martínez, J., 2008. The effect of surface finishes on outdoor granite and limestone pavers. Materiales de Construccion 58 (289-290), 65-79.

Gómez-Heras, M., Figueiredo, C., Varas, M.J., Mauricio, A., Álvarez de Buergo, M., AiresBarros, L., Fort, R., 2006. Digital image analysis contribution to the evaluation of the mechanical decay of granitic stones affected by fires. In: Kourkoulis, S.K. (Ed.), Fracture and Failure of Natural Building Stones. Applications in the Restoration of Ancient Monuments. Springer-Verlag, Dordrecht, pp. 427-438.

Gonzalez-Casado, J.M., Caballero, J.M., Casquet, C., Galindo, C., Tornos, F., 1996. Palaeostress and geotectonic interpretation of the Alpine Cycle onset in the Sierra del Guadarrama (eastern Iberian Central System), based on evidence from episyenites. Tectonophysics 262, 213-229.

Goudie, A., Viles, H., 1997. Salt Weathering Hazards. John Wiley \& Sons, Chichester. Chapter 4, 241 pp.

Helmi, F.M., 1985. Deterioration of some granite in Egypt. Proceedings of the Vth International Congress on Deterioration and Conservation of Stone. Presses Polytechniques Romandes. Laboratoire de conservation de la Pierre. Ecole Polytecnique Federale de Lausanne 1, 421-425.

Haneef, S.J., Johnson, J.B., Jones, M., Thompson, G.E., Wood, G.C., Azzaz, S.A, 1993. A laboratory simulation of degradation of leinster granite bydry and wet deposition processes. Corrosion Science 34 (3), 511-524.

Hodson, M.E., Lee, M.R., Parsons, I., 1997. Origins of the surface roughness of unweathered alkali feldspar grains. Geochimica et Cosmochimica Acta 61 (18), 3885-3896.

Holdren Jr., G.R., Speyer, P.M., 1985. Reaction rate surface area relationships during the early stages of weathering-I. initial observations. Geochimica et Cosmochima Acta 49, 675-681.

Holdren Jr., G.R., Speyer, P.M., 1987. Reaction rate surface area relationships during the early stages of weathering-II. Date on eight additional feldspars. Geochimica et Cosmochima Acta 51, 2311-2318.

ISO 4287:1984. Surface roughness-terminology: Part 1. Surface and its parameters. International Organization for Standardization.

ITGE, Instituto Tecnológico y Geominero de España, 1990. Mapa Geológico Nacional (MAGNA), 1:50.000. Hoja 533 (San Iorenzo de El Escorial). $2^{\mathrm{a}}$ serie, $1^{\mathrm{a}}$ Edición.

Jermy, C.A., Bell, F.G., 1998. Durability of some dolerites from South Africa. Proceedings of the 8th International Congress of IAEG, vol 4, pp. 2869-2875. Balkema, Vancouver.

Jiménez-Espinosa, R., Vázquez, M., Jimenez-Millan, J., 2007. Differential weathering of granitic stocks and landscape effects in a Mediterranean climate, Southern Iberian Massif (Spain). Catena 70, 243-252.

Lasaga, A.C., Blum, A.E., 1986. Surface chemistry, etch pits and mineral-water reactions. Geochimica et Cosmochimica Acta 50 (10), 2363-2379.

Lee, M.R., Parsons, I., 1995. Microtextural controls of weathering of perthitic alkali feldspars. Geochimica et Cosmochimica Acta 59 (21), 4465-4488.

Lee, M.R., Hodson, M.E., Parsons, I., 1998. The role of intragranular microtextures and microstructures in chemical and mechanical weathering: direct comparisons of experimentally and naturally weathered alkali feldspars. Geochimica et Cosmochimica Acta 62 (16), 2771-2788.

Marques, E.A.,. Vargas Jr., E.A, 1998. Geotechnical characterization of weathering profiles in biotite gneiss (kinzigites) from Rio de Janeiro City. Mineralogical changes and physical properties. Proceedings of the 8th International Congressof IAEG, vol. 4, pp. 2673-2680. Balkema, Vancouver.

Matias, J.M.S., Alves, C.AS., 2001. In: Lourenço, P.B., Roca, P. (Eds.), Decay patterns of granite stones in Braga monuments (NW Portugal). Historical Constructions, Guimarães, pp. 363-371.

Menduiña, J., Fort, R., García delCura, M.A., Galán, L., Pérez-Soba, C., Perez-Monserrat, E.M., Fernández-Revuelta, B., Bernabéu, A., Varas, M.J., 2005. Las piedras utilizadas en la construcción de los bienes de interés cultural de la Comunidad de Madrid anteriores al siglo XXX. Instituto Geológico y Minero de España, Madrid. 131 pp.

Meyer, H.J., Iacmann, R., Zimmermann, H., 1994. Random space filling by nucleation and growth. Journal of Crystal Growth 135 (3-4), 571-586.

Moore, D.E., Lockner, D.A, 1995. The role of microcracking in shear-fracture propagation in granite. Journal of Structural Geology 17 (1), 95-114.

Mosquera, M.J., Rivas, T., Prieto, B., Silva, B., 2000. Capillary rise in granitic rocks: interpretation of kinetics on the basis of pore structure. Journal of Colloid and Interface Science 222 (1), 41-45.

Nicholson, D.T., 2001. Pore properties as indicators of breakdown mechanisms in experimentally weathered limestones. Earth Surface Processes and Landforms 26 , 819-838.

Onishi, C.T., Shimizu, I., 2005. Microcrack networks in granite affected by a fault zone: visualization by confocal laser scanning microscopy. Journal of Structural Geology 27 (12), 2268-2280.

Pérez-Monserrat, E., Fort, R., 2004. Caracterización y procedencia de la piedra de sillería granítica del Convento de la Encarnación (Madrid). Geo-temas 6 (1), 89-92.

Rivas, T., Prieto, B., Silva, B., 2000. Influence of rift and bedding plane on the physicomechanical properties of granitic rocks. Implications for the deterioration of granitic monuments. Building and Environment 35, 387-396.

Rivas, T., Prieto, B., Silva, B., 2008. Ensayos de alteración artificial aplicados a rocas graníticas (Artificial weathering of granite). Materiales de Construccion 58 (289290), 179-189.

Røyne, A., Jamtveit, B., Mathiesen, J., Malthe-Sørenssen, A., 2008. Controls on rock weathering rates by reaction-induced hierarchical fracturing. Earth and Planetary Science Letters 275 (3-4), 364-369.

Ruiz de Argandoña, V.G., Calle ja, L., Montoto, M., Suárez del Río, L.M., Rodríguez Rey, A., 1988. Petrophysical interpretation of the acoustic emission activity in heated crystalline rocks. Proceedings of the 9th International Acoustic Emission Symposium, pp. 82-291. Kobe (Japan). 
Scherer, G.W., 1999. Crystallization in pores. Cement and Concrete Research 29 (8), 1347-1358.

Scherer, G.W., Flatt, R., Wheeler, G, 2001. Materials science research for the conservation of sculpture and monuments. MRS Bulletin 26, 44-50.

Schiavon, N., Chiavari, G., Schiavon, G., Fabbric, D., 1995. Nature and decay effects of urban soiling on granitic building stones. Science of the Total Environment 167 (1-3), $87-101$.

Schiavon, N., 2002. Biodeterioration of calcareous and granitic building stones in urban environments. In: Siegesmund, S., Weiss, T., Vollbrecht, V.A (Eds.), Natural Stone, Weathering Phenomena, Conservation Strategies and Case Studies: Geological Society of Iondon Special Publication, voL 205, pp. 195-206.

Schiavon, N., 2007. Kaolinisation of granite in an urban environment. Environmental Geology 52, 399-407

Seo, Y.S., Jeong, G.C., Kim, J.S., Ichikawa, Y., 2002. Microscopic observation and contact stress analysis of granite under compression. Engineering Geology 63, 259-275.

Sousa, L.M.O., 2007. Granite fracture index to check suitability of granite outcrops for quarrying. Engineering Geology 92, 146-159.

Sousa, L.M.O., Suarez del Rio, L.M., Calle ja, L., Ruiz de Argandoña, V.G., Rodríguez-Rey, A., 2005. Influence of microfractures and porosity on the physico-mechanical properties and weathering of ornamental granites. Engineering Geology 77 $153-168$.

Suzuki, K., Oda, M., Kuwahara, T., Hirama, K., 1995. Material property changes in granitic rock during long term immersion in hot water. Engineering Geology 40, 29-39.

Suzuki, K., Oda, M., Yamazaki, M., Kuwahara, T., 1998. Permeability changes in granite with crack growth during immersion in hot water. International Journal of Rock Mechanics and Mining Sciences and Geomechanics Abstracts 35 (7), 907-921.
UNE-EN 12370:1999. Natural stone test methods. Determination of resistance to salt crystallisation. AENOR (Spanish Association for Standardisation and Certification), $12 \mathrm{pp}$.

UNE-EN 1936:1999. Natural stone test methods. Determination of real density and apparent density, and of total and open porosity. AENOR (Spanish Association for Standardisation and (ertification), $14 \mathrm{pp}$

UNE-EN 14579:2005. Natural stone test methods. Determination of sound speed propagation. AENOR (Spanish Association for Standardisation and Certification), 16 pp.

UNE-EN 1936:2007 Natural stone test methods. Determination of real density and apparent density, and of total and open porosity. AENOR (Spanish Association for Standardisation and Certification).

Villaseca, C, 2003. Sobre elorigen del batolito granítico del Sistema Central español (On the origin of the granitic batholith of the Spanish Central System). Boletín de la Real Sociedad Española de Historia Natural 98, 23-39.

Villaseca, C, Barbero, L, Rogers, G., 1998. Crustal origin of Hercynian peraluminous granitic batholiths of Central Spain: petrological, geochemical and isotopic ( $\mathrm{Sr}, \mathrm{Nd}$ ) constraints. Lithos 43 (2), 55-79.

Villaseca, C, Herreros, V., 2000. A sustained felsic magmatic system: the Hercynian granitic batholith of the Spanish Central System. Transactions of the Royal Society of Edinburgh: Earth Sciences 91, 207-219.

Walker, 1990. Ion mircroprobe study of intragrain micropermeability in alkali feldspar Contributions to Mineralogy and Petrology 106, 124-128.

Walter F.D.L, 1991. Micropores in Alkali Feldspars. Unpublished Ph.D. thesis. University of Edinburgh.

Winkler, E.M., 1997. Stone in Architecture: Properties and Durability, 3rd ed. SpringerVerlag, Berlin. 309 pp. 